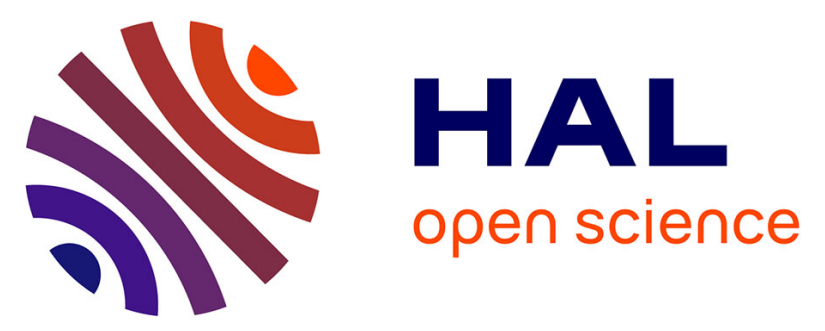

\title{
Interplay between bulk atomic clusters and surface structure in complex intermetallic compounds: The case study of the Al5Co2(001) surface
}

M. Meier, J. Ledieu, M.-C. De Weerd, Ying-Tzu Huang, G. J. P. Abreu, K. Pussi, R. D. Diehl, T. Mazet, V. Fournée, É. Gaudry

\section{To cite this version:}

M. Meier, J. Ledieu, M.-C. De Weerd, Ying-Tzu Huang, G. J. P. Abreu, et al.. Interplay between bulk atomic clusters and surface structure in complex intermetallic compounds: The case study of the Al5Co2(001) surface. Physical Review B: Condensed Matter and Materials Physics (1998-2015), 2015, 91, pp.085414. 10.1103/PhysRevB.91.085414 . hal-01132752

\section{HAL Id: hal-01132752 \\ https://hal.science/hal-01132752}

Submitted on 17 Mar 2015

HAL is a multi-disciplinary open access archive for the deposit and dissemination of scientific research documents, whether they are published or not. The documents may come from teaching and research institutions in France or abroad, or from public or private research centers.
L'archive ouverte pluridisciplinaire HAL, est destinée au dépôt et à la diffusion de documents scientifiques de niveau recherche, publiés ou non, émanant des établissements d'enseignement et de recherche français ou étrangers, des laboratoires publics ou privés. 


\title{
Interplay between bulk atomic clusters and surface structure in complex intermetallic compounds: The case study of the $\mathrm{Al}_{5} \mathrm{Co}_{2}(001)$ surface
}

\author{
M. Meier, ${ }^{1}$ J. Ledieu, ${ }^{1}$ M.-C. De Weerd,${ }^{1}$ Ying-Tzu Huang, ${ }^{2}$ G. J. P. Abreu, ${ }^{2}$ K. Pussi, ${ }^{3}$ R. D. Diehl,,${ }^{2}$ T. Mazet, ${ }^{1}$ \\ V. Fournée, ${ }^{1}$ and É. Gaudry ${ }^{1, *}$ \\ ${ }^{1}$ Institut Jean Lamour, UMR CNRS 7198, Université de Lorraine, 54011 Nancy cedex, France \\ ${ }^{2}$ Department of Physics, Penn State University, University Park, Pennsylvania 16802, USA \\ ${ }^{3}$ Lappeenranta Univ. Technol., Dept Math. \& Phys., FIN-53851 Lappeenranta, Finland
}

(Received 4 November 2014; published 13 February 2015)

\begin{abstract}
The $\mathrm{Al}_{5} \mathrm{Co}_{2}$ crystal is a complex intermetallic compound, whose structure can be described by a stacking of chemically bonded atomic motifs. It is a potentially new catalytic material for heterogeneous hydrogenation. A single crystal of this phase has been grown by the Czochralski technique in order to study the influence of the three-dimensional bulk substructure on the two-dimensional surface using both experimental ultrahigh vacuum surface techniques and $a b$ initio methods based on the density functional theory. Some bulk properties are first presented, focusing on chemical bond strengths, the determination of the $\mathrm{Al}$ and Co chemical potentials in $\mathrm{Al}_{5} \mathrm{Co}_{2}$, the vibrational properties, and the specific heat. Then, the combination of experimental and computational approaches allows the identification of the surface structure, which was found to depend on the surface preparation conditions. In all cases, the surface terminates at specific bulk layers (Al-rich puckered layers) where various fractions of specific sets of $\mathrm{Al}$ atoms are missing, identified as $\mathrm{Al}_{3}$ atoms left at the surface resulting from cluster truncation. Finally, electron density of states calculations and spectroscopic measurements were compared and indicate a strong $s p$ - $d$ hybridization of the topmost pure Al layer with subsurface Co atoms. This could influence the surface reactivity and the catalytic performances of this material.
\end{abstract}

DOI: 10.1103/PhysRevB.91.085414

PACS number(s): 68.35.bd, 61.66.Dk

\section{INTRODUCTION}

Recent advances in heterogeneous hydrogenation catalysis have identified transition-metal aluminides as promising candidates for the development of cheap catalytic materials with improved performances [1,2]. Prototypes of these aluminides are $\mathrm{Al}_{13} T M_{4}$ compounds ( $T M=\mathrm{Co}$ or $\mathrm{Fe}$ ) belonging to a family of complex intermetallic compounds known as periodic approximants of Al-based decagonal quasicrystals [2]. These $\mathrm{Al}_{13} T M_{4}$ compounds are crystalline phases with large unit cells possessing a local atomic order close to that of their quasicrystalline counterparts [3,4]. In particular, their structure can be described as a packing of highly symmetric clusters, connected by additional glue atoms. The catalytic performances of these materials have been ascribed to the existence of small, stable, and well-separated atomic ensembles containing active transition-metal elements, defining the so-called site-isolation concept $[2,5,6]$. The stability of these atomic ensembles is strongly linked to the cluster substructure and the $3 d$ chemical bonding network. Therefore, it is interesting to understand the relationship that exists between chemically bonded bulk clusters and surface atomic ensembles to which the catalytic properties are ascribed.

In this paper, we focus on the related $\mathrm{Al}_{5} \mathrm{Co}_{2}$ complex intermetallic compound, which is also an approximant to decagonal quasicrystals [7] and a good candidate for catalytic purposes [8]. Although its unit cell (28 atoms per unit cell) is relatively small compared to that of $\mathrm{Al}_{13} T M_{4}$ crystals (102 atoms per unit cell), it is an ideal system to understand the relationship between three-dimensional bulk clusters and two-dimensional surfaces. Indeed, $\mathrm{Al}_{5} \mathrm{Co}_{2}$ shares many

*Emilie.Gaudry@univ-lorraine.fr similarities with quasicrystalline phases, i.e., with systems of higher complexity. First, it is a Hume-Rothery phase. Its bulk electronic structure shows a pseudogap at the Fermi level energy, which results from both a $s p-d$ hybridization and a strong Fermi surface/Brillouin zone interaction [9]. Second, its atomic structure resembles that of decagonal phases, with local pentagonal atomic configurations. Chemical bonding in $\mathrm{Al}_{5} \mathrm{Co}_{2}$ has already been investigated using the electron localizability indicator (ELI) approach, revealing covalentlike two-center bonds which define two types of atomic motifs in the bulk structure [10], i.e., one three-dimensional cluster and one planar motif (see Fig. 1). Here, we would like to understand if and how these bulk atomic motifs influence the surface structure and if the concept of site isolation could be relevant in this case.

The $\mathrm{Al}_{5} \mathrm{Co}_{2}$ compound initially reported in [11] belongs to the space group $P 6_{3} / m m c$ ( $h P 28$, space group 194) with lattice parameters $a=b=7.6717 \AA, c=7.6052 \AA$ [12-14]. The unit cell contains five inequivalent atomic positions (Table I). According to the bulk model, two types of atomic layers with the same atomic density are stacked along the [001] direction as shown in Fig. 1: pure $\mathrm{Al}$ puckered layers (7 $\mathrm{Al}$ atoms per layer) and flat layers containing both $\mathrm{Al}$ and $\mathrm{Co}$ atoms (4 $\mathrm{Co}$ and $3 \mathrm{Al}$ atoms per layer).

The $(2 \overline{1} 0)$ and (001) surfaces have been recently investigated using first-principles calculations [15]. The relative stability of possible bulk terminated surfaces has been compared. In the case of the (001) surface, it was concluded that surface terminations at Al-rich bulk layers should be preferred over mixed Al/Co layers. These results could not be compared to any experimental observations, due to the lack of single crystals required for experimental surface studies. In this work, we describe the successful growth of a large single grain of the $\mathrm{Al}_{5} \mathrm{Co}_{2}$ phase by the Czochralski technique. The goal 


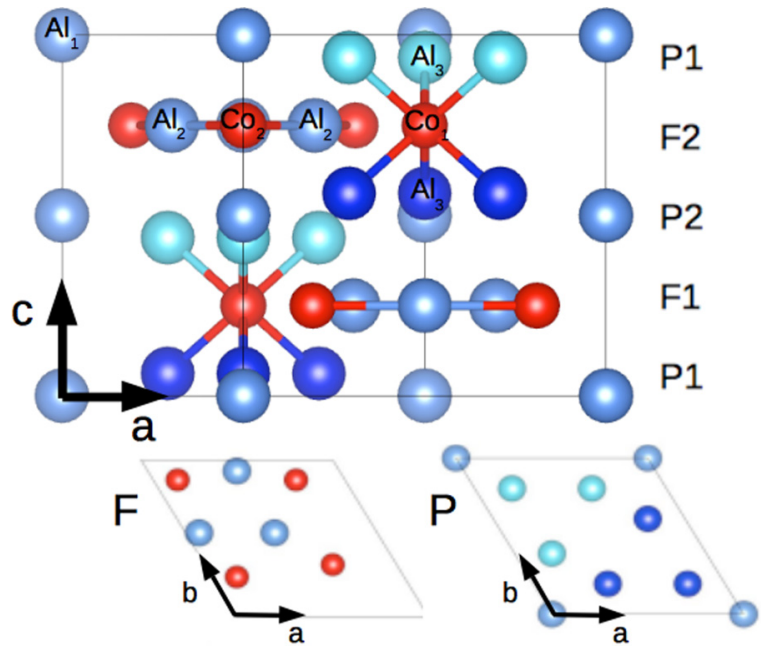

FIG. 1. (Color online) Atomic structure of $\mathrm{Al}_{5} \mathrm{Co}_{2}$. Top: layer stacking along the [001] direction. The layers P1 and P2, or F1 and F2, are related to each other by a rotation of $180^{\circ}$. Bottom: in-plane structure of the flat $(\mathrm{F})$ and puckered $(\mathrm{P})$ layers. Co atoms are displayed in red, $\mathrm{Al}$ atoms at the mean plane position (in the $\mathrm{P}$ layer) and in the $\mathrm{F}$ layer are in blue, $\mathrm{Al}$ atoms above the mean plane position in the $\mathrm{P}$ layer are in dark blue, and $\mathrm{Al}$ atoms below are in light blue.

here is the investigation of the $\mathrm{Al}_{5} \mathrm{Co}_{2}(001)$ surface structure, which is achieved through a combination of both theoretical and experimental results. The experimental approach, under ultrahigh vacuum (UHV) conditions, includes x-ray photoelectron spectroscopy (XPS), low-energy electron diffraction (LEED), and scanning tunneling microscopy (STM), while the theoretical approach is based on the density functional theory (DFT). To fully interpret the results obtained for the surface, a precise knowledge of the bulk structure and properties is required, and this is also presented in this paper. Regarding the bulk properties, we focus here on the evaluation of chemical bond strengths, the determination of the $\mathrm{Al}$ and Co chemical potentials in $\mathrm{Al}_{5} \mathrm{Co}_{2}$, and the analysis of bulk vibrational properties. This experimental and first-principles study will allow us to fully interpret the observed surface reconstructions and to understand its relationship with the underlying cluster substructure of the bulk.

The paper is organized as follows. Section II summarizes the experimental and computational details. Section III is divided into three subsections: the first one focuses on bulk thermodynamic, electronic, and vibrational properties, and the second part deals with the (001) surface taking into consideration the influence of preparation conditions. The combination

TABLE I. Atomic positions in $\mathrm{Al}_{5} \mathrm{Co}_{2}$ [13].

\begin{tabular}{cccccc}
\hline \hline Site & Wickoff & $x$ & $y$ & $z$ & Sublattice \\
\hline $\mathrm{Al}_{1}$ & $2 a$ & 0 & 0 & 0 & $\alpha_{1}$ \\
$\mathrm{Al}_{2}$ & $6 h$ & 0.5355 & 0.0710 & $\frac{1}{4}$ & $\alpha_{2}$ \\
$\mathrm{Al}_{3}$ & $12 k$ & 0.1944 & 0.3888 & 0.0614 & $\alpha_{3}$ \\
$\mathrm{Co}_{1}$ & $2 c$ & $\frac{1}{3}$ & $\frac{2}{3}$ & $\frac{1}{4}$ & $\beta_{1}$ \\
$\mathrm{Co}_{2}$ & $6 h$ & 0.8726 & 0.7452 & $\frac{1}{4}$ & $\beta_{2}$ \\
\hline \hline
\end{tabular}

of the experimental and computational approaches allows for the identification of the surface structure. Results are discussed in the third subsection. Here, the $\mathrm{Al}_{5} \mathrm{Co}_{2}(001)$ surface structure is compared to surface structures of related $\mathrm{Al}-\mathrm{Co}$ complex metallic alloys. The final section summarizes the main results of the paper.

\section{METHODS}

\section{A. Experimental methods \\ 1. Crystal growth}

According to the phase diagram by Gödecke and Ellner, the $\mathrm{Al}_{5} \mathrm{Co}_{2}$ is an incongruently melting intermetallic compound [16]. Single-crystal growth can be achieved from an Al-rich solution at a temperature below its peritectic transformation at $1426 \mathrm{~K}$. The initial composition of the Al-rich solution was selected according to the phase diagram $\left(\mathrm{Al}_{76} \mathrm{Co}_{24}\right)$. A homogeneous solution was first prepared by precisely weighing metallic pieces ( $3 N$ grade) to the desired composition and premelting under Ar atmosphere using an induction furnace. The premelted ingot was then placed in an alumina crucible in the Czochralski furnace, initially evacuated to a pressure of $10^{-6} \mathrm{mbar}$ and back-filled with 700 mbar Ar (5.0 grade). A small single crystal with undefined orientation obtained from a previous growth experiment was used as a seed. The seed was brought into contact with the liquid solution at a temperature of 1400-1426 K and then pulled at a rate of $2 \mathrm{~mm} / \mathrm{h}$. This resulted in single-crystal growth of several $\mathrm{cm}$ in length and about $1 \mathrm{~cm}$ in diameter. The chemical homogeneity of the crystal was checked by energy dispersive $\mathrm{x}$-ray analysis and the composition was found to be consistent with the known compositional range of the $\mathrm{Al}_{5} \mathrm{Co}_{2}$ compound, i.e., $\mathrm{Al}_{71.1-72.0} \mathrm{Co}_{28.9-28}$ according to Bradley [17] or possibly narrower according to Stein et al. [18]. For surface investigation, a sample with a surface oriented perpendicular to the [001] axis using back reflection Laue was cut from the ingot. Another smaller crystal with dimensions $1.72 \times 2.64 \times 2.78 \mathrm{~mm}^{3}$ (total mass of $55 \mathrm{mg}$ ) was prepared for specific-heat measurements.

\section{Specific heat}

Specific-heat measurements were performed in the temperature range between 2 and $30 \mathrm{~K}$ by using a Quantum Design Physical Property Measurement System (PPMS) that employs an automated thermal relaxation calorimeter.

In the case of nonmagnetic intermetallic compounds, the specific heat is expressed by the sum of the electronic and lattice specific heats. The electronic specific heat $C_{e l}(T)=\gamma T$ depends linearly on the temperature, with $\gamma=\frac{\pi^{2}}{3} k_{B}^{2} n\left(E_{F}\right)$, where $n\left(E_{F}\right)$ is the electronic density of states at the Fermi level expressed in units of states/eV atom and $C_{e l}(T)$ is in $\mathrm{mJ} / \mathrm{mol} \mathrm{K}^{2}$. The lattice specific heat at low temperature, below about $10 \mathrm{~K}$, can be approximated by the Debye model: $C_{\text {latt }}(T)=\alpha T^{3}$. The $\alpha$ coefficient is related to the Debye temperature by $\Theta_{D}=\left(\frac{12 \pi^{4} R}{5 \alpha}\right)^{1 / 3}$, where $R$ is the gas constant. This Debye temperature can be compared with the theoretical value within the Debye model: $\Theta_{D}=\left(\frac{6 N}{\pi}\right)^{\frac{1}{3}} \frac{h v_{S}}{2 L k_{B}}$ where $L$ is the lattice parameter, $k_{B}$ the Boltzmann constant, $h$ the Planck constant, $v_{S}$ the sound velocity, and $N$ the number of atoms. 


\section{Surface methods}

The $\mathrm{Al}_{5} \mathrm{Co}_{2}(001)$ surface was first polished using diamond paste down to $0.25 \mu \mathrm{m}$ and mounted on a Ta plate before being inserted into the UHV system with a base pressure of $2.10^{-11}$ mbar. A clean surface was achieved by repeated cycles of $\mathrm{Ar}^{+}$sputtering (1.5 keV for $30 \mathrm{~min}$ ) and annealing at $973 \mathrm{~K}$ (unless specified in the text) for 1-h periods. The temperature was measured by an optical pyrometer with an emissivity set to 0.35 . The surface composition and cleanliness was verified by XPS using a nonmonochromated $\mathrm{Mg} K \alpha$ x-ray source. The surface structure was investigated by LEED and STM while the surface electronic structure was probed by roomtemperature ultraviolet photoelectron spectroscopy (UPS) and scanning tunneling spectroscopy (STS). All experiments were performed in the same UHV system. Dynamical LEED-IV measurements were performed at Penn State University in a separate UHV chamber with a base pressure of $1.10^{-10}$ mbar and equipped with facilities for sample preparation. The LEED experiments were performed with an $\mathrm{OCI}^{\mathrm{TM}}$ LEED instrument. The crystal was prepared by cycles of $\mathrm{Ar}^{+}$ sputtering (1.5 keV for $30 \mathrm{~min}$ ) and annealing at significantly higher temperature than previously mentioned $(1180 \mathrm{~K}$ for $1 \mathrm{~h}$ ). The LEED patterns were recorded at room temperature and at $134 \mathrm{~K}$ at normal incidence using a CCD camera. The in-house data acquisition software HOTLEED was used to record LEED patterns at $1-\mathrm{eV}$ intervals in the range of $20-400 \mathrm{eV}$. The LEED spot intensities of 84 diffracted beams were extracted using the in-house EASYLEED software [19]. These intensities were symmetry averaged to obtain 14 independent beams. The total energy range of these 14 beams is $3626 \mathrm{eV}$. The structure analysis was carried out using symmetrized automated tensor LEED (SATLEED) [20]. The scattering phase shifts $\left(1_{\max }=\right.$ 12) that describe the scattering potential were calculated using the EEASISS program [21]. The agreement between the experimental and calculated curves was measured using the Pendry $R$ factor [22] and its variance was used to determine the uncertainties.

\section{B. Computational methods}

Complementary to the experimental study, the $\mathrm{Al}_{5} \mathrm{Co}_{2}$ compound was investigated by performing DFT calculations using the plane-wave Vienna $a b$ initio simulation package (VASP) [23-26]. The interaction between the valence electrons and the ionic core is described using the projectoraugmented wave (PAW) method [27,28] and the calculations are performed within the generalized gradient approximation (GGA-PBE) [29,30]. Atomic structures were plotted using VESTA [31].

\section{Bulk thermodynamic properties}

Total-energy calculations on the bulk model were realized using a cutoff energy $\left(E_{\text {cut }}\right)$ and a number of $k$ points within the Brillouin zone such as to achieve an energy precision lower than $0.06 \mathrm{meV} /$ atom $\left(E_{\text {cut }}=450 \mathrm{eV}\right.$ and $k$-points grid set to $8 \times 8 \times 8)$.

The study of point-defect concentrations in $\mathrm{Al}_{5} \mathrm{Co}_{2}$ is useful for further surface calculations since it allows us to determine the range of the allowed chemical potentials in the compound and to calculate the surface energies. Most of the surface models studied for the $\mathrm{Al}_{5} \mathrm{Co}_{2}(001)$ surface have some specific atoms removed and are thus no longer at stoichiometry. For this reason, the surface energies are plotted as a function of the chemical potential $\mu_{\mathrm{Al}}$. Here, calculations of point defects are performed with $2 \times 2 \times 2$ supercells. The supercell size is chosen to avoid interactions between single defects while being consistent with the experimental compositional range. Indeed, the presence of one defect in the simulation cell results in the compositional range $\mathrm{Al}_{71.0-71.7} \mathrm{Co}_{29.0-28.3}$, in reasonable agreement with the compositional range derived experimentally $\left(\mathrm{Al}_{71.1-72.0} \mathrm{Co}_{28.9-28}\right)$. No interstitial positions were taken into account. The statistical model used in this study is an extension to five sublattices for the five inequivalent atomic positions (see Table I) of the model developed by Hagen and Finnis in the case of two sublattices [32]. Each site of each sublattice is occupied either by its own atom (Al for $\alpha$ sites and Co for $\beta$ sites) or an atom of the other kind (an antisite defect) or a vacancy. Therefore, 10 defects are considered: vacancies on sublattices $\alpha_{1}, \alpha_{2}, \alpha_{3}, \beta_{1}, \beta_{2}\left(\mathrm{~V}^{\alpha_{1}}\right.$, $\left.\mathrm{V}^{\alpha_{2}}, \mathrm{~V}^{\alpha_{3}}, \mathrm{~V}^{\beta_{1}}, \mathrm{~V}^{\beta_{2}}\right), \mathrm{Al}$ atoms in antisite position on $\beta_{1}$ or $\beta_{2}$ sites $\left(\mathrm{Al}_{1}^{\beta}, \mathrm{Al}_{2}^{\beta}\right)$, Co atoms in antisite position on $\alpha_{1}, \alpha_{2}$, or $\alpha_{3}$ sites $\left(\mathrm{Co}^{\alpha_{1}}, \mathrm{Co}^{\alpha_{2}}, \mathrm{Co}^{\alpha_{3}}\right)$. At constant temperature and pressure, the defects concentrations, their formation energies, and the chemical potentials are obtained by Gibbs energy minimization in the canonical ensemble, following the method proposed by Colinet et al. [33-35]. In this study, the direct influence of pressure variations has been neglected, then the minimization of the Gibbs energy $(G)$ has been replaced by the free energy $(F)$.

In this paper, we also determine the bonding strengths $E_{S_{1}-S_{2}}$, through the formation energy of nearest-neighbor vacancies:

$$
E_{S_{1}-S_{2}}=E_{f}\left(S_{1}, S_{2}\right)-E_{f}\left(S_{1}\right)-E_{f}\left(S_{2}\right),
$$

where $E_{f}\left(S_{1}, S_{2}\right)$ is the formation energy of the dual vacancy $\left(S_{1}-S_{2}\right)$ and $E_{f}\left(S_{i}\right)$ is the formation energy of the single vacancy $S_{i}$. A total of 14 different possible bonds between nearest neighbors have been tested.

\section{Bulk vibrational properties}

Dynamical and thermodynamical properties of bulk $\mathrm{Al}_{5} \mathrm{Co}_{2}$ were investigated using first-principles calculations density functional perturbation theory (DFPT). A force constant method is used in which the second derivative of the total energy is evaluated for all pairs of atoms $i$ and $j$. The dynamical matrix $D(k)$ is constructed on a dense mesh of $k$ points and the phonon frequencies are evaluated. To guarantee the accuracy of the calculations, a $\Gamma$-centered $8 \times 8 \times 8 k$-point grid and a $500 \mathrm{eV} E_{\text {cut }}$ were used for the bulk. Phonon frequencies were obtained from force constants using the PHONOPY package [36]. Different $k$ meshes were tested, up to $48 \times 48 \times 48$.

The specific heat at constant volume $C_{v}$ is deduced from the previous phonon calculations within the Debye model:

$$
C_{v}=\int_{0}^{\infty} k_{B}\left(\frac{\hbar \omega}{k_{B} T}\right)^{2} \frac{e^{\beta \hbar \omega}}{\left(e^{\beta \hbar \omega}-1\right)^{2}} g(\omega) d \omega .
$$


The specific heat at constant pressure $\left(C_{p}\right)$ is obtained by applying the following correction:

$$
C_{p}=C_{v}+\alpha^{2} B T V,
$$

where $\alpha$ is the thermal expansion coefficient and $B$ the bulk modulus. $B$ is obtained by fitting the calculated total energy as a function of the volume of the bulk unit cell around $\pm 0.5 \%$ of its optimized value using a Birch-Muraghan equation of state [37]. The thermal expansion coefficient $\alpha$ is obtained by

$$
\alpha(T)=\frac{1}{B V} \sum_{i} \gamma_{i} C_{v_{i}}(T),
$$

where $\gamma_{i}$ is the Grüneisen parameter for the state $i$, obtained by comparing the phonon density of states of the bulk with the phonon density of states of the bulk with a reduced unit-cell volume $(-0.1 \%):-\gamma_{i} \frac{\delta V}{V}=\frac{\delta \omega_{i}}{\omega_{i}}$ with $\omega_{i}$ the phonon frequency of states $i$ and $V$ the unit-cell volume.

\section{Surface calculations}

The (001) surface is modeled by an 11-layer-thick slab separated by an additional 5-layer void thickness. The $k$ mesh was adjusted to $8 \times 8 \times 1$. The 7 layers at the bottom of the slab were fixed while atoms in the 4 top layers were allowed to relax. These slab parameters are the result of a set of test calculations to guarantee that (i) the distance between the last fixed layer and the first relaxed layer $(d)$ is close to the bulk interlayer distance $\left(d_{0}\right):\left|d-d_{0}\right| / d=\sim 1 \%$, (ii) the forces on the last fixed layer are weaker than $\sim 0.06 \mathrm{eV} / \AA$, (iii) the void thickness between slabs is large enough to avoid interactions between two consecutive slabs. Spin polarization was also considered and was found unnecessary in the present case.

Surface energies have been computed with asymmetric slabs using a method described in Refs. [38-41]. Within this approach, the surface energy is given as a function of the $\mathrm{Al}$ and Co chemical potentials:

$$
\left(\gamma_{\text {bot }}+\gamma_{\text {top }}\right) \times A=E^{\text {slab }}-\mu_{\mathrm{Al}} N_{\mathrm{Al}}^{\text {slab }}-\mu_{\mathrm{Co}} N_{\mathrm{Co}}^{\text {slab }},
$$

where $\gamma_{\text {bot }}$ is the surface energy of the fixed bottom surface of the slab, $\gamma_{\text {top }}$ the surface energy of the surface model we are looking for, $A$ the surface area, $E^{\text {slab }}$ the total energy of the slab, $\mu_{i}$ (resp. $\mu_{i}^{\text {bulk})}$ is the chemical potential (resp. cohesive energy) of element $i$, and $N_{i}^{\text {slab }}$ the number of atoms of element $i$ in the slab.

Using $\mu_{\mathrm{Al}_{5} \mathrm{Co}_{2}}^{\text {bulk }}=5 \mu_{\mathrm{Al}}+2 \mu_{\mathrm{Co}}$, the surface energy can be expressed as a function of $\left(\mu_{\mathrm{Al}}-\mu_{\mathrm{Al}}^{\text {bulk }}\right)$ :

$$
\begin{aligned}
\gamma_{\text {top }}= & \frac{1}{A}\left[E^{\text {slab }}-\frac{N_{\mathrm{Co}}^{\text {slab }}}{2} \mu_{\mathrm{Al}_{5} \mathrm{Co}_{2}}^{\text {bulk }}-N_{\mathrm{Al}}^{\text {slab }} \mu_{\mathrm{Al}}^{\text {bulk }}\right. \\
& \left.+\frac{5 N_{\mathrm{Co}}^{\text {slab }}}{2} \mu_{\mathrm{Al}}^{\text {bulk }}\right]-\gamma_{\text {bot }}+\frac{1}{A}\left[\frac{5 N_{\mathrm{Co}}^{\text {slab }}}{2}-N_{\mathrm{Al}}^{\text {slab }}\right] \\
& \times\left(\mu_{\mathrm{Al}}-\mu_{\mathrm{Al}}^{\text {bulk }}\right),
\end{aligned}
$$

where $\gamma_{\text {bot }}$ is determined using a symmetric slab without relaxations.

Restricting ourselves to trends in the stability of surfaces for different stoichiometries, the derivation of proper chemical potentials can be avoided. Although exact values cannot be determined, one can still set rigorous bounds to the range of $\mu_{i}$ values as long as the surface system is in equilibrium. In particular, each $\mu_{i}$ must satisfy $\mu_{i} \leqslant \mu_{i}^{\text {bulk }}$. Due to variations of surface preparation conditions, the exact value of chemical potential is unknown but we can estimate its range by

$$
\Delta H_{f} \times \frac{7}{5}<\mu_{\mathrm{Al}}-\mu_{\mathrm{Al}}^{\text {bulk }}<0,
$$

where $\Delta H_{f}$ is the formation enthalpy in $\mathrm{eV} /$ atom, linked to $\mu_{\mathrm{Al}_{5} \mathrm{Co}_{2}}^{\text {bulk }}$ through $\mu_{\mathrm{Al}_{5} \mathrm{Co}_{2}}^{\text {bulk }}=5 \mu_{\mathrm{Al}}^{\text {bulk }}+2 \mu_{\mathrm{Co}}^{\text {bulk }}+\Delta H_{f} \times 7$.

This approach does not consider entropic contributions. We have used a simple statistical model to estimate the contribution from configurational entropy to the surface energy associated with the existence of domains (see Sec. III), leading to small values on the order of a few $\mathrm{mJ} \mathrm{m}^{-2}$. A better estimation of the vibrational entropy contribution would require the calculation of the phonon DOS for the different surface models. However, such calculations are computationally too expensive due to the size of the slabs.

\section{RESULTS}

\section{A. Bulk properties}

\section{Bulk thermodynamic properties}

Geometry optimization calculations for bulk $\mathrm{Al}_{5} \mathrm{Co}_{2}$ result in good agreement with the experimental lattice parameters $\left(a_{\text {calc }}, b_{\text {calc }}=7.67 \AA, c_{\text {calc }}=7.59 \AA\right.$, and $a_{\text {expt }}, b_{\text {expt }}=7.67 \AA$, $c_{\text {expt }}=7.61 \AA$ ). The difference between calculated total energy using the experimental and calculated lattice parameters is lower than $1 \mathrm{meV}$. The corresponding formation energy is $-0.46 \mathrm{eV} /$ atom, in agreement with the experimental value $(-0.43 \mathrm{eV} /$ atom [42]) and other calculated values $(-0.48$ $\mathrm{eV} /$ atom [43], $-0.46 \mathrm{eV} /$ atom [15], $-0.45 \mathrm{eV} /$ atom [44]). The bulk modulus is calculated to be $0.82 \mathrm{eV} / \AA^{3}$ (130 GPa), in agreement with the calculated value from Ref. [44] (116 GPa). The cohesive energy $\mu_{\mathrm{Al}_{5} \mathrm{Co}_{2}}^{\text {bulk }}$ was calculated to be $-32.41 \mathrm{eV}$ per $\mathrm{Al}_{5} \mathrm{Co}_{2}$ motif.

The study of deviation from the perfect stoichiometry is done by introducing defects. In $\mathrm{Al}_{5} \mathrm{Co}_{2}$, our single defect calculations identify two types of constitutional defects. For the Co-rich region, the constitutional defects are Co antisites while for the Al-rich region, constitutional defects are $\mathrm{Co}$ vacancies. These calculated constitutional defects are the same as those obtained on the simple B2-AlCo alloy [45]. More precisely, the constitutional defects in $\mathrm{Al}_{5} \mathrm{Co}_{2}$ are vacancies on the $\beta_{1}$ sublattice (Al-rich region) and Co antisites on the $\alpha_{1}$ sublattice (Co-rich region). The variations of the calculated defect concentrations at $300 \mathrm{~K}$ as a function of the chemical composition are shown in Fig. 2. The concentrations at 1000 $\mathrm{K}$ show the same behavior but with a smaller dispersion. The defect concentrations are very small at $300 \mathrm{~K}$, in agreement with the small compositional range determined experimentally for $\mathrm{Al}_{5} \mathrm{Co}_{2}\left(\mathrm{Al}_{71.1-72.0} \mathrm{Co}_{28.9-28}\right)$ : Co antisite concentration is 0.6 at. \%, Co vacancy concentration is 0.9 at.\%, while other concentrations can be neglected. In the following, we will consider as a first approximation a perfectly stoichiometric $\mathrm{Al}_{5} \mathrm{Co}_{2}$ sample. 


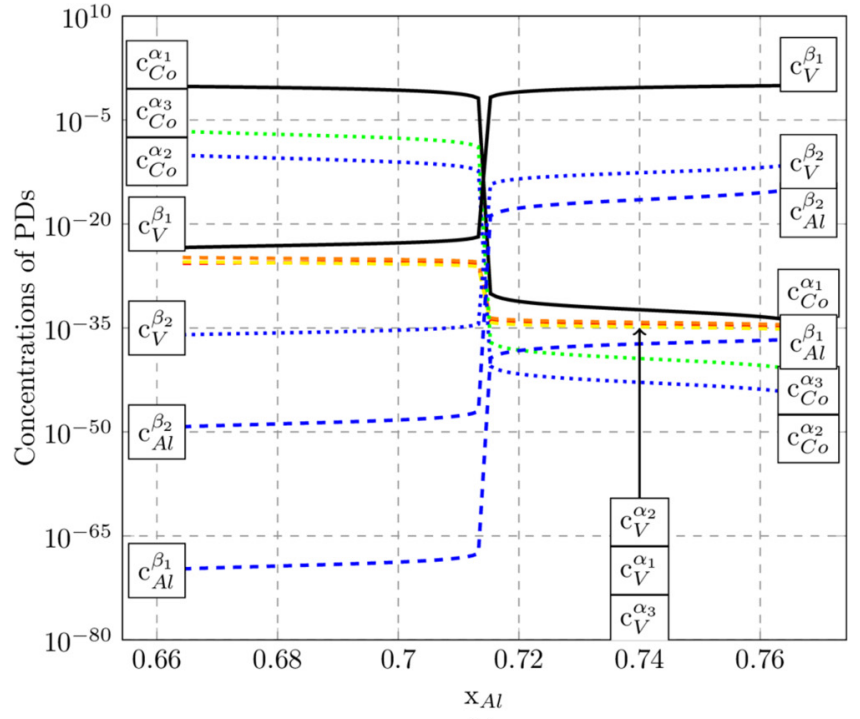

(a)

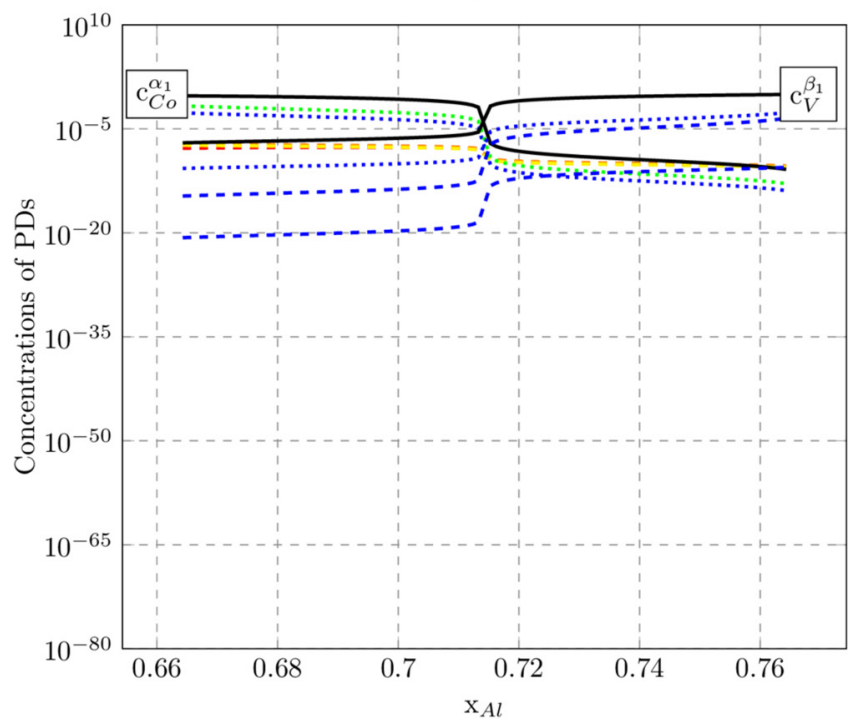

(b)

FIG. 2. (Color online) (a) Defect concentrations at $300 \mathrm{~K}$ as a function of the chemical composition, (b) defect concentrations at $1000 \mathrm{~K}$ as a function of the chemical composition. The color code in (b) is the same as in (a).

Figure 3 shows the formation energies $e_{\text {type }}^{\text {sublattice }}$ for the different defects. They are given by

$$
\begin{aligned}
& e_{V}^{\alpha_{1}}=E\left(N, V^{\alpha_{1}}\right)-E(N)+\mu_{\mathrm{Al}}, \\
& e_{V}^{\beta_{1}}=E\left(N, V^{\beta_{1}}\right)-E(N)+\mu_{\mathrm{Co}}, \\
& e_{\mathrm{Co}}^{\alpha_{1}}=E\left(N, \mathrm{Co}^{\alpha_{1}}\right)-E(N)+\mu_{\mathrm{Al}}-\mu_{\mathrm{Co}}, \\
& e_{\mathrm{Al}}^{\beta_{1}}=E\left(N, \mathrm{Al}^{\beta_{1}}\right)-E(N)-\mu_{\mathrm{Al}}+\mu_{\mathrm{Co}},
\end{aligned}
$$

where $E(N, X)$ is the energy of the supercell with defect $X$ and $E(N)$ the energy of the supercell without defect.

The defect concentrations depend on the $\mathrm{Al}$ and Co chemical potentials, whose values as a function of the chemical composition (at $300 \mathrm{~K}$ ) are shown in Fig. 3. At $0 \mathrm{~K}$, the chemical potential of $\mathrm{Al}$ in $\mathrm{Al}_{5} \mathrm{Co}_{2}$ (Al-rich part) is close to the one of pure Al. The difference between the two chemical
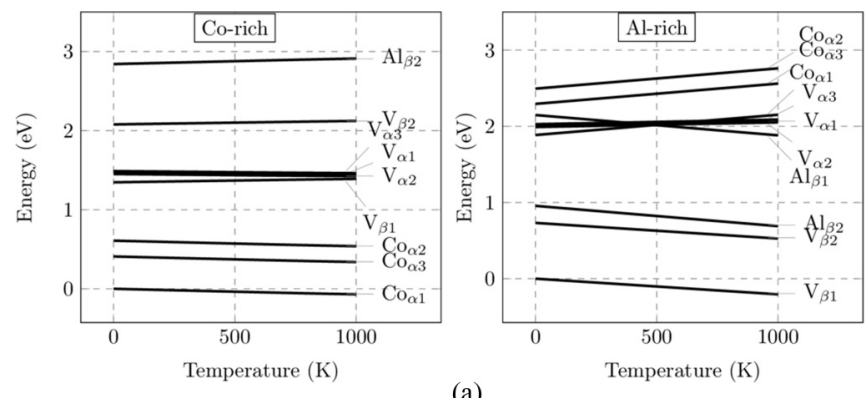

(a)
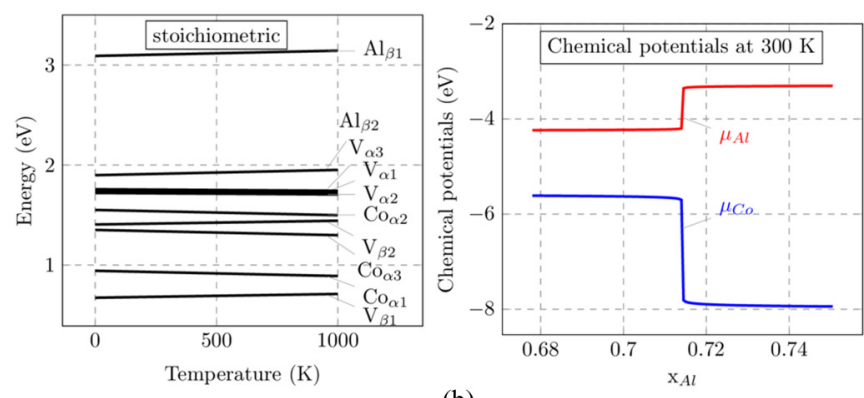

(b)

FIG. 3. (Color online) Defect formation energies in $\mathrm{Al}_{5} \mathrm{Co}_{2}$ (in $\mathrm{eV}$ ) for (a) Al-rich side and Co-rich side, (b) for stoichiometric $\mathrm{Al}_{5} \mathrm{Co}_{2}$ and chemical potentials at $300 \mathrm{~K}$ as a function of the chemical composition in $\mathrm{Al}_{5} \mathrm{Co}_{2}$.

potentials is found to be $0.03 \mathrm{eV}$ where $\mu_{\mathrm{Al}}^{\text {bulk }}=-3.50 \mathrm{eV}$, in agreement with Ref. [46] (-3.39 eV). Similarly, the chemical potential of $\mathrm{Co}$ in $\mathrm{Al}_{5} \mathrm{Co}_{2}$ (Co-rich part) is close to the one of pure $\mathrm{Co}\left(\mu_{\mathrm{Co}}^{\text {bulk }}=-5.83 \mathrm{eV}, \mu_{\mathrm{Co}}^{\mathrm{Al}_{5} \mathrm{Co}_{2}}=-5.96 \mathrm{eV}\right)$. Then, the allowed range of $\left(\mu_{\mathrm{Al}}-\mu_{\mathrm{Al}}^{\text {bulk }}\right)$ deduced from single defect calculations $([-0.60 ;-0.03] \mathrm{eV})$ is very close to the allowed range of $\left(\mu_{\mathrm{Al}}-\mu_{\mathrm{Al}}^{\text {bulk }}\right)$ obtained from a simple thermodynamic approach [Eq. (7), [-0.65 eV; $0 \mathrm{eV}]]$.

As mentioned before, this paper aims to understand the relationship between chemically bonded bulk atomic motifs and surface atomic ensemble. Therefore, we evaluated bonding strengths in $\mathrm{Al}_{5} \mathrm{Co}_{2}$ through total-energy calculations (Table II). We found that the strongest bonds are $\mathrm{Al}_{3}-\mathrm{Co}_{1}$ $(0.49 \mathrm{eV})$ and $\mathrm{Al}_{2}-\mathrm{Co}_{2}(0.40 \mathrm{eV})$ bonds. These are bonds involved in the three-dimensional structure of $\mathrm{Al}_{5} \mathrm{Co}_{2}$ : the three-dimensional cluster involves $\mathrm{Al}_{3}-\mathrm{Co}_{1}$ bonds while the planar motif involves $\mathrm{Al}_{2}-\mathrm{Co}_{2}$ bonds. It is worth noticing that these two types of atomic motifs are linked through weaker Al-Co bondings, namely, $\mathrm{Al}_{2}-\mathrm{Co}_{1}(0.26 \mathrm{eV})$ and $\mathrm{Al}_{3}-\mathrm{Co}_{2}$ $(0.30$ and $0.24 \mathrm{eV})$ bonds. The aluminium atoms of $\mathrm{Al}_{1}$ type play the role of glue atoms, connecting motif sites. Our results

TABLE II. Distances (in $\AA$ ) and bonding energies (in $\mathrm{eV}$ ) of the strongest bonds in $\mathrm{Al}_{5} \mathrm{Co}_{2}$.

\begin{tabular}{llcc}
\hline \hline & Bonds & Distance & Bonding energy \\
\hline $\mathrm{Al}_{2}$ & $\mathrm{Co}_{2}$ & 2.40 & -0.40 \\
$\mathrm{Al}_{2}$ & $\mathrm{Co}_{1}$ & 2.69 & -0.26 \\
$\mathrm{Al}_{3}$ & $\mathrm{Co}_{1}$ & 2.34 & -0.49 \\
$\mathrm{Al}_{3}$ & $\mathrm{Co}_{2}$ & 2.53 & -0.30 \\
$\mathrm{Al}_{3}$ & $\mathrm{Co}_{2}$ & 2.69 & -0.24 \\
\hline \hline
\end{tabular}



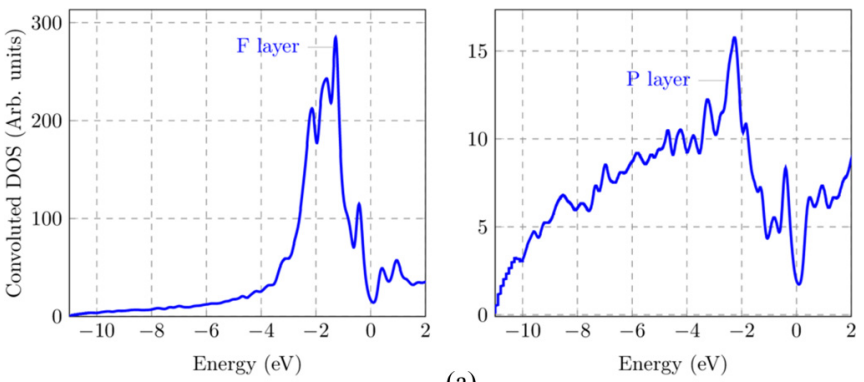

(a)
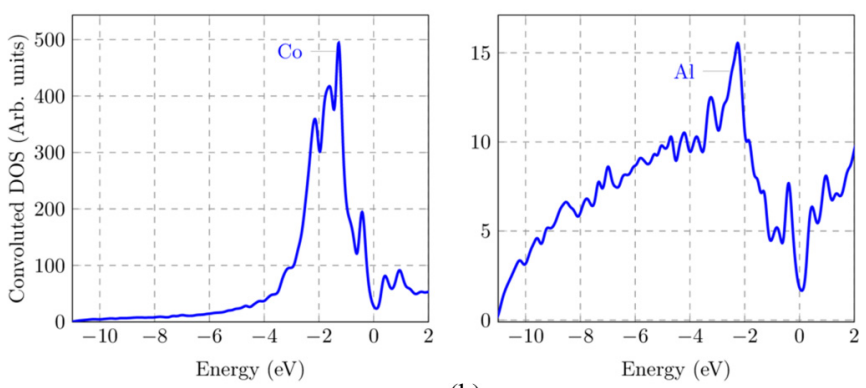

(b)

FIG. 4. (Color online) Convoluted DOS in bulk $\mathrm{Al}_{5} \mathrm{Co}_{2}$. (a) Contribution of the $\mathrm{P}$ and $\mathrm{F}$ layers, (b) contributions of $\mathrm{Co}$ and $\mathrm{Al}$ atoms (partial DOS).

are in good agreement with the ELI calculations of Ref. [10], which identified two two-center bonds $\left(\mathrm{Al}_{3}-\mathrm{Co}_{1}\right.$ and $\left.\mathrm{Al}_{2}-\mathrm{Co}_{2}\right)$ as the origin of the description of the $\mathrm{Al}_{5} \mathrm{Co}_{2}$ structure as a packing of atomic motifs.

\section{Bulk electronic structure}

Figure 4 shows the calculated DOS of the bulk projected on either F or P layers as well as partial Co and Al DOS. All calculated DOS curves are convoluted with a Gaussian ( $\sigma$ $=0.08 \mathrm{eV}$ ) to account for thermal broadening. The results are in agreement with previous calculations using the tightbinding linear muffin-tin orbital (TB-LMTO) approach $[9,47]$ or methods based on the density functional theory [15]. At low binding energy, the DOS has a parabolic shape due to nearly free-electron $s p$ states. The broad peak of Co $d$ states lies in the middle of the $s p$ band. The DOS presents a pseudogap at the Fermi energy. The density of states at the minimum of the pseudogap is 0.12 states/(eV atom), in agreement with the experimental value of 0.14 states/(eV atom) (see next part) as well as with previous calculations by Trambly de Laissardière et al. [9]. This low value corresponds to about $\frac{1}{3}$ of the DOS of pure aluminium at the Fermi level.

The presence of common peaks in the Al $s p$ and Co $d$ DOS (Fig. 4) for the bulk system suggests a relatively strong mixing of the two sets of electronic states, characteristic of a covalent character of the Al-Co bonds. This is in agreement (i) with the shape of the electron density isosurface calculated for bulk $\mathrm{Al}_{9} \mathrm{Co}_{2}$ [48], showing a nonhomogeneous total charge density distribution between $\mathrm{Al}$ and $\mathrm{Co}$ atoms and (ii) with the difference between the total charge density and the superposition of atomic charge density plotted in Fig. 5, showing an enhanced charge distribution along connections between $\mathrm{Al}$ and $\mathrm{Co}$ atoms. This is especially noticeable for the strongest bonds identified previously. Indeed, a positive charge

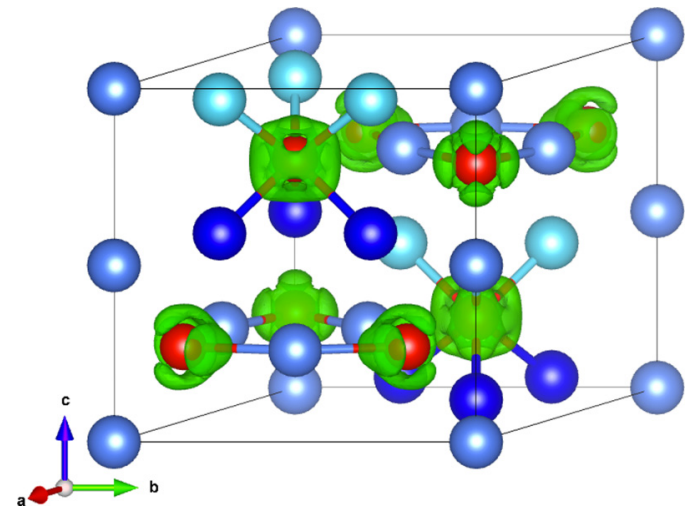

FIG. 5. (Color online) Isodensity surface $\left(0.015 e^{-} / \AA^{-3}\right)$ of the difference between the total charge density and the superposition of atomic charge densities. The strongest bonds within the two types of atomic motifs are displayed. Only $\mathrm{Al}_{1}$-type atoms and atoms involved in the considered motifs are shown.

difference along the $\mathrm{Co}-\mathrm{Al}$ bonding $\left(\mathrm{Co}_{2}-\mathrm{Al}_{2}\right)$ is visible. However, this charge difference does not consist in a single lobe along the $\mathrm{Co}_{2}-\mathrm{Al}_{2}$ bond, but presents a more complex shape. The positive charge difference contributions, visible on top and below the $\mathrm{Co}$ atom $\left(\mathrm{Co}_{2}\right.$ type $)$, is matching with the two weaker bonds identified previously, namely, the $\mathrm{Co}_{2}-\mathrm{Al}_{3}$ and $\mathrm{Co}_{1}-\mathrm{Al}_{2}$ bonds. Similar conclusions can be drawn from the charge distribution in the three-dimensional $\left(\mathrm{Co}_{1}\right)\left(\mathrm{Al}_{3}\right)_{6}$ cluster, where not only the $\mathrm{Al}_{3}-\mathrm{Co}_{1}$ strong bond but also an additional $\mathrm{Co}_{1}-\mathrm{Al}_{2}$ bond has to be considered.

\section{Bulk vibrational properties}

The phonon density of states (VDOS) $g(\omega)$ and phonon band structure are shown in Fig. 6. The calculated VDOS is in agreement with a previous report by Mihalkovič et al. [43,49]. While the contribution of Co atoms is limited to low frequencies [below $30 \mathrm{meV}$, see Fig. 6(b)], the contribution of $\mathrm{Al}$ atoms expands over the whole spectrum.

The sound velocities are evaluated from the three smallest eigenvalues of the dynamical matrix near the $\Gamma$ point of the Brillouin zone [49]. We assigned the two smallest eigenvalues to the transverse modes and the third to the longitudinal mode. The mean sound velocity $v_{S}$ is given by $\frac{3}{v_{S}^{3}}=\frac{2}{v_{T}^{3}}+\frac{1}{v_{L}^{3}}$ where $\mathrm{v}_{T}$ and $\mathrm{v}_{L}$ are the transverse and longitudinal velocities. From the phonon dispersion, we deduced $v_{L} \sim 6750 \mathrm{~m} \mathrm{~s}^{-1}, v_{T} \sim$ $3990 \mathrm{~m} \mathrm{~s}^{-1}$, and $v_{S} \sim 4420 \mathrm{~m} \mathrm{~s}^{-1}$. These values are in reasonable agreement with those published in Ref. [49] computed using $a b$ initio or semiempirical potentials Al-Co pair potentials $\left(\mathrm{v}_{L}=4920-6579 \mathrm{~m} \mathrm{~s}^{-1}, \mathrm{v}_{T}=3350-3670 \mathrm{~m} \mathrm{~s}^{-1}\right.$, and $\mathrm{v}_{S}=$ $3650-4080 \mathrm{~m} \mathrm{~s}^{-1}$ ).

The previous theoretical results are supplemented by specific-heat measurements $\left(C_{p}\right.$, see Fig. 7). Between 2 and $10 \mathrm{~K}$, there is a good agreement between the experimental data and the calculated specific heat within the Debye model. The Debye temperature deduced from the experimental data is equal to $600 \mathrm{~K}$. It is in agreement with the value deduced from the Debye model $(550 \mathrm{~K})$. In addition, we deduced from these data a value of $n\left(E_{F}\right)$ equal to 0.14 states/eV atom, which is in good agreement with our previous electron DOS calculations 

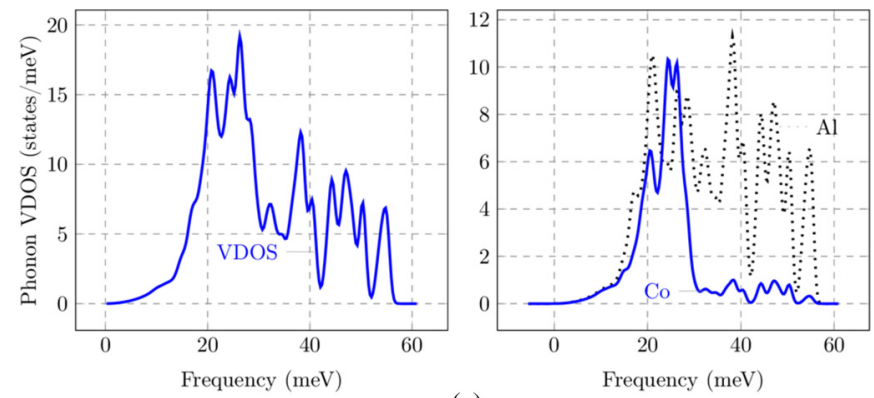

(a)

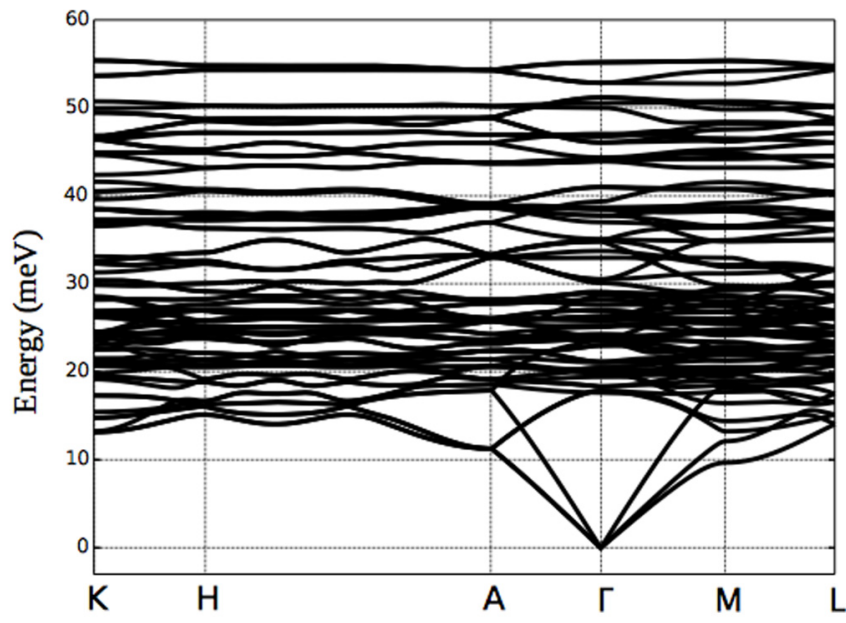

(b)

FIG. 6. (Color online) (a) Calculated vibrational density of states for $\mathrm{Al}_{5} \mathrm{Co}_{2}$ and contributions of $\mathrm{Al}$ and Co to the VDOS. Full line is for $\mathrm{Co}$ atoms and dashed line is for $\mathrm{Al}$ atoms, (b) phonon dispersion relations along high-symmetry directions $\left[K\left(\frac{2}{3}, \frac{2}{3}, 0\right), H\left(\frac{2}{3}, \frac{2}{3}, \frac{1}{2}\right)\right.$, $\left.A\left(0,0, \frac{1}{2}\right), \Gamma(0,0,0), M\left(\frac{1}{2}, 0,0\right), L\left(\frac{1}{2}, 0, \frac{1}{2}\right)\right]$.

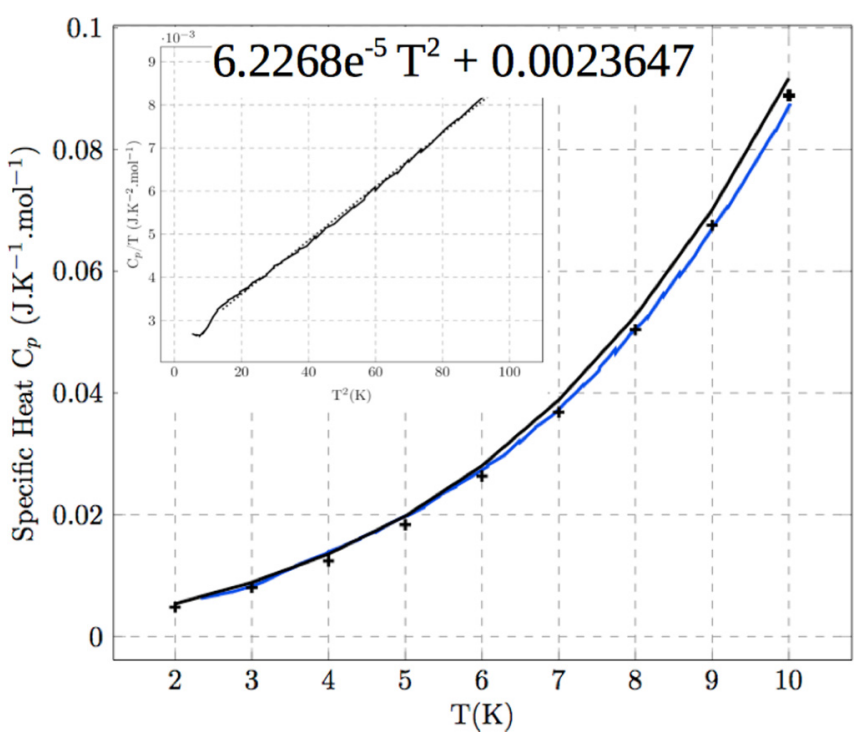

FIG. 7. (Color online) Specific-heat measurement for the $\mathrm{Al}_{5} \mathrm{Co}_{2}$ compound (solid blue curve) compared with the calculated one (solid black curve). The contribution of phonons is represented by the dots. The inset shows a fit of the low-temperature data in a $C_{p} / T$ versus $T^{2}$ plot. The equation corresponds to $C_{p} / T=\alpha T^{2}+\gamma$, with $\alpha$ and $\gamma$ the coefficients related the lattice specific heat and the electronic specific heat determined by the fit.
(0.12 states/eV atom) as well as previous literature values (0.12 states/eV atom) [47,50], thus confirming the Hume-Rothery character of the $\mathrm{Al}_{5} \mathrm{Co}_{2}$ compound.

\section{B. $\mathrm{Al}_{5} \mathrm{Co}_{2}(001)$ surface}

We now turn to the description of the $\mathrm{Al}_{5} \mathrm{Co}_{2}(001)$ surface. In a first step, we present separately the experimental results obtained by annealing the sample at $973 \mathrm{~K}$ and theoretical results, mainly surface energy calculations for various surface models. Then, all results are combined to propose a structural model of the surface.

\section{Experimental results}

The chemical composition of the (001) near surface region has been measured by XPS as a function of the photoelectron takeoff angle (between $0^{\circ}$ to $60^{\circ}$ with respect to the surface normal) to vary the surface sensitivity. The composition is derived from the area of the $\mathrm{Al} 2 p$ and Co $2 p_{3 / 2}$ core levels after subtracting the $\mathrm{Mg} K \alpha$ satellites. A Shirley background was removed from the Al $2 p$ spectrum while a linear or a Touggard background was found to be more appropriate in the case of the Co $2 p_{3 / 2}$ line. The measured area for each core level has been corrected by a normalization coefficient as described in [48]. The results are shown in Fig. 8(a) and indicate an almost constant concentration with varying surface sensitivity. Therefore, we assume that no large surface segregation occurs. The measured $\mathrm{Al}$ content varies from $77 \pm 5$ at. $\%$ to $80 \pm 5$ at. $\%$ depending on the type of background used, i.e., higher than the theoretical content $\left(\mathrm{Al}_{71.4} \mathrm{Co}_{28.6}\right)$, but within the error bars associated with quantitative XPS analysis. The Al $2 p$ and Co $2 p_{3 / 2}$ core-level spectra are shown in Figs. 8(b) and $8(\mathrm{c})$. The Al $2 p$ core levels can be fitted with two asymmetric lines separated by $0.41 \mathrm{eV}$ to account for the unresolved $2 p_{3 / 2}$ and $2 p_{1 / 2}$ components. Interestingly, the Co $2 p$ levels exhibit a sizable satellite at $5 \mathrm{eV}$ on the high binding energy side of the main line, representing about $10 \%$ of the total intensity. A similar satellite peak has also been reported in a CoAl intermetallic compound [51], whereas it is usually very weak in pure Co metal [52]. The origin of the satellite in transition-metal core levels is usually attributed to a different screening channel during the photoionization process. A well-known example is the Ni 6-eV satellite [53]. There, the main peak in $\mathrm{Ni} 2 p_{3 / 2}$ spectrum is attributed to a $c^{-1} 3 d^{10} 4 s^{1}$ final state $\left(c^{-1}\right.$ is the core hole) where an additional charge from the $s p$ conduction band can occupy a $d$ orbital, leading to the formation of the $3 d^{10}$ configuration. The satellite peak corresponds to a $c^{-1} 3 d^{9} 4 s^{2}$ final state where, although the Ni $d$ band is now fully below $E_{F}$, it is not filled by an additional screening electron. The wide $\mathrm{Ni} 4 s$ band instead produces the screening. In the case of the Co $2 p_{3 / 2}$ spectrum, the main peak is attributed to $c^{-1} 3 d^{9} 4 s^{1}$ final state and the satellite peak to $c^{-1} 3 d^{8} 4 s^{2}$ final state. The position and strength of the satellite depend on the electronic correlations, the electronic band structure, and the crystal structure itself. Therefore, the occurrence of a strong satellite structure in the Co $2 p_{3 / 2}$ spectrum of the $\mathrm{Al}_{5} \mathrm{Co}_{2}$ compound reflects a change in $\mathrm{Co}$ $d$ - $d$ interactions and/or in $s p$ - $d$ hybridization in the compound compare to pure Co metal. 


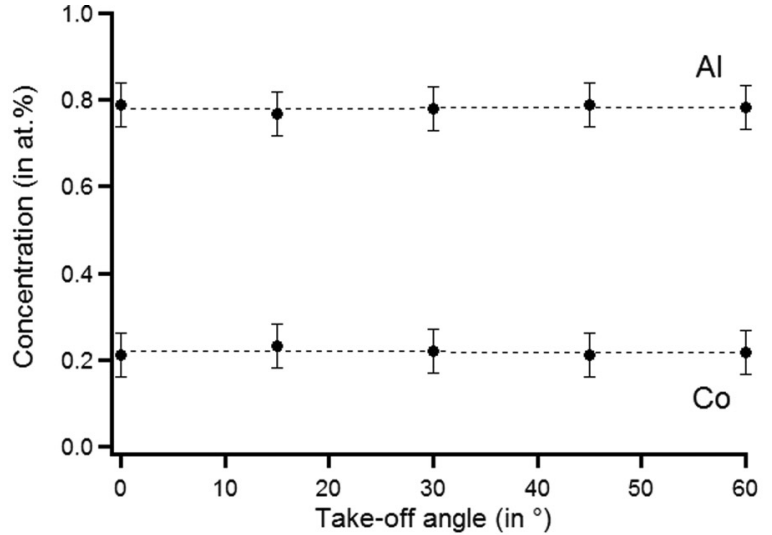

(a)

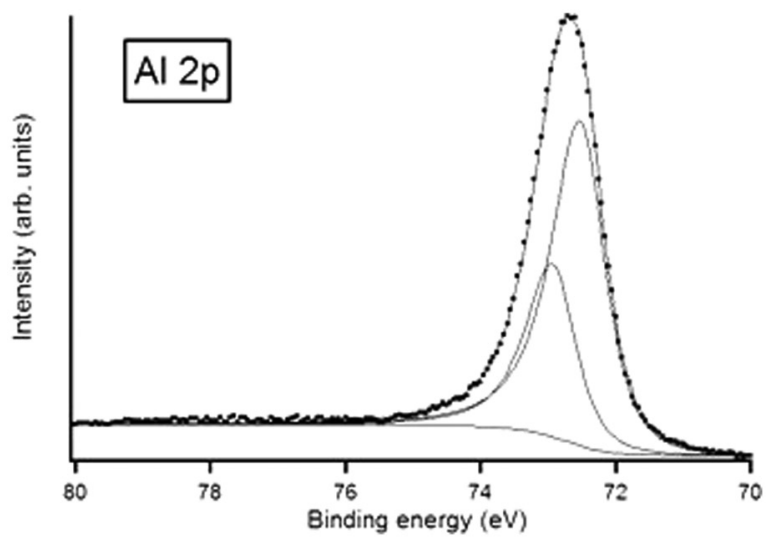

(b)

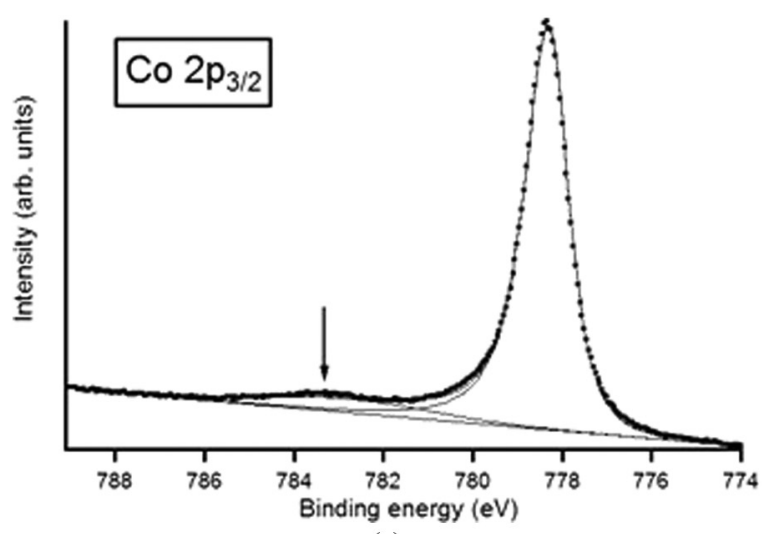

(c)

FIG. 8. (a) Variation of the elemental composition at the (001) surface of $\mathrm{Al}_{5} \mathrm{Co}_{2}$ as a function of the photoelectron takeoff angle. The measurements at $60^{\circ}$ are more surface sensitive than those performed at $0^{\circ}$. The dotted lines are only guides for the eyes. (b), (c) XPS Al $2 p$ and Co $2 p_{3 / 2}$ core-level lines, respectively, measured at $0^{\circ}$ takeoff angle. Dots represent the experimental spectra and thin lines are the deconvoluted spectra. The arrow in (c) outlines the position of the satellite peak in the Co $2 p_{3 / 2}$ spectrum.

A typical LEED pattern of the clean $\mathrm{Al}_{5} \mathrm{Co}_{2}(001)$ surface is shown Fig. 9 after annealing the sample at $973 \mathrm{~K}$. To calibrate the momentum space, diffraction patterns of a reference $\operatorname{Ag}(111)$ surface have been recorded under identical conditions. The sharpest diffraction spots of the LEED pattern

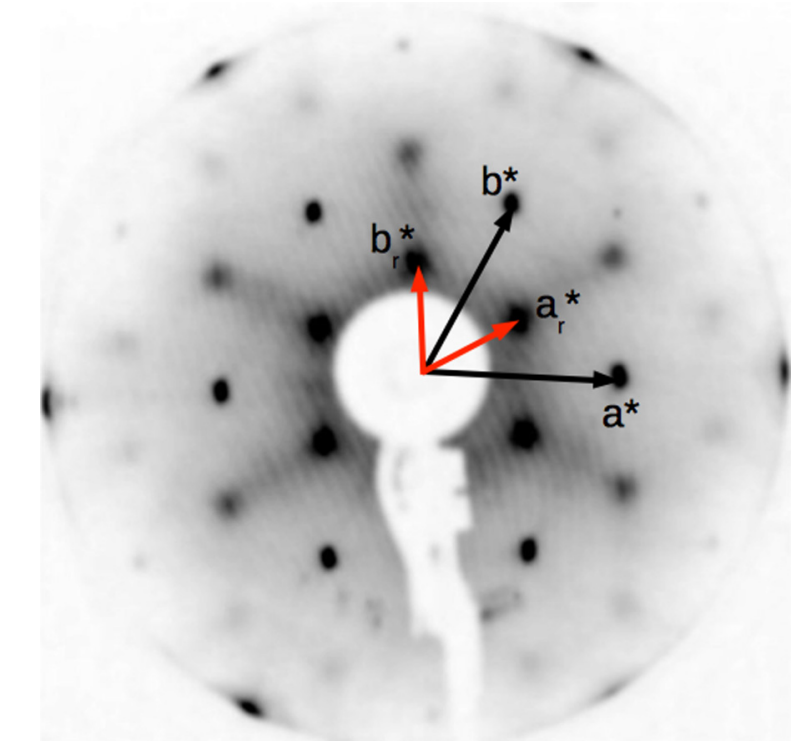

FIG. 9. (Color online) LEED pattern at $20 \mathrm{eV}$ of the $\mathrm{Al}_{5} \mathrm{Co}_{2}(001)$ surface prepared at high temperature $(973 \mathrm{~K})$ showing a $(\sqrt{3} \times$ $\sqrt{3}) R 30^{\circ}$ reconstruction.

in Fig. 9 correspond to a hexagonal unit mesh with $a=b=$ $7.3 \pm 0.4 \AA$, consistent with a bulk terminated surface. The uncertainty is estimated from systematic errors arising from distance measurements in the LEED images or changes in sample position during LEED acquisition. Additional diffraction spots characterized by a more diffuse character indicate a $(\sqrt{3} \times \sqrt{3}) R 30^{\circ}$ reconstruction. Some diffuse intensities can also be observed along lines connecting the most diffuse spots. The dimensions of the reconstructed lattice are estimated at $13.5 \pm 0.4 \AA \sim \sqrt{3} \times a$.

A typical STM image of the surface prepared at this temperature is shown in Fig. 10(a). It shows a terrace and step morphology with a unique step height of $3.8 \pm 0.2 \AA$, corresponding to approximately $c / 2$. The structure of the $\mathrm{Al}_{5} \mathrm{Co}_{2}$ compound along the [001] direction as shown in Fig. 1 consists in a periodic stacking of alternating flat $(\mathrm{F})$ and puckered (P) atomic layers. The measured step height corresponds to the distance between two consecutive either $\mathrm{F}$ or P layers, suggesting that only one of the two possible

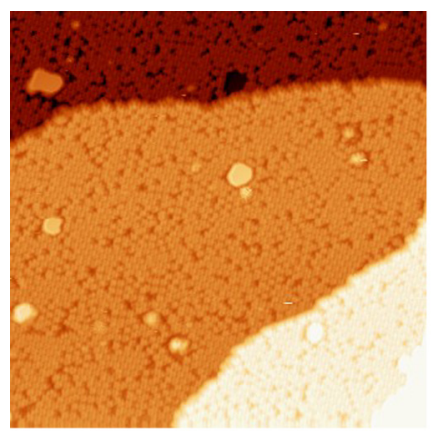

(a)

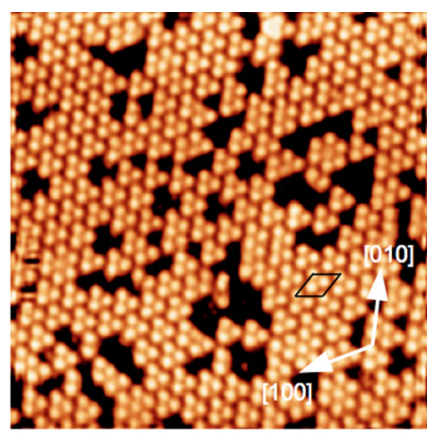

(b)
FIG. 10. (Color online) STM images $(-2 \mathrm{~V}, 0.1 \mathrm{nA})$ of the $\mathrm{Al}_{5} \mathrm{Co}_{2}(001)$ surface prepared at $973 \mathrm{~K}$. (a) $70 \times 70 \mathrm{~nm}^{2}$, (b) $20 \times 20 \mathrm{~nm}^{2}$. 
terminations appears at the surface. The high-resolution STM image shown in Fig. 10(b) reveals small atomic ensembles with a triangular shape. The edge length of these ensembles is $7.6 \pm 0.3 \AA$, corresponding to the dimensions of the primitive surface lattice. The distance between adjacent triangular motifs is $13 \pm 0.5 \AA \sim \sqrt{3} \times a$, thus defining the lattice of the $(\sqrt{3} \times \sqrt{3}) R 30^{\circ}$ reconstruction observed in the LEED pattern. This reconstructed hexagonal lattice contains a significant density of defects imaged as a dark area with pseudotriangular shapes. The defects are vacancies and are $\sim 2 \AA$ deep. The existence of domains (discussed in Sec. III C) in the surface lattice is consistent with the observed diffuse LEED spots associated with the $(\sqrt{3} \times \sqrt{3}) R 30^{\circ}$ reconstruction. The fastFourier transforms (FFT) of STM images show features similar to the LEED patterns, with sharp spots associated with the primitive lattice and more diffuse spots associated with the reconstruction (not shown). The bright features randomly distributed on terraces in Fig. 10(a) are 3 to $6 \AA$ high and are probably extrinsic defects which can be related to either surface preparation or to the single crystal itself. Based on XPS analysis, we rule out the possibility of surface contamination.

\section{Theoretical results}

In order to propose a surface model accounting for the above experimental observations, various surface models have been built from both F and P bulk terminations. Previous surface studies of Al-based intermetallic compounds have shown that their surface usually terminates at dense Al-rich bulk planes, which would correspond to $\mathrm{P}$ layers in this case as already pointed out in [15] [Fig. 11(a)]. By removing different groups of atoms from the P-terminated surface, one obtains two different models which geometrically fit the reconstruction, presenting triangular-shaped atomic ensembles having the

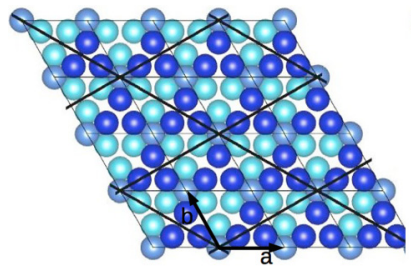

(a)

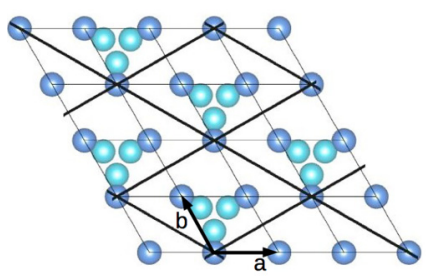

(c)

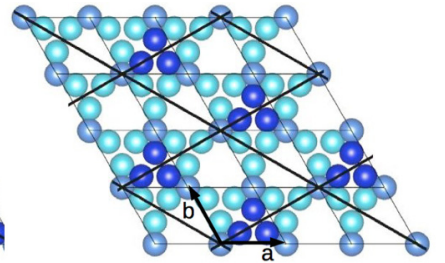

(b)

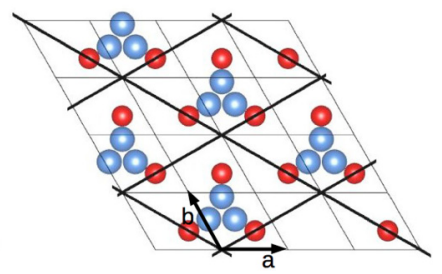

(d)
FIG. 11. (Color online) Topmost layer for (a) complete P layer

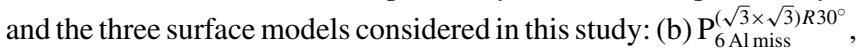
(c) $\mathrm{P}_{15 \mathrm{Almiss}}^{(\sqrt{3} \times \sqrt{3}) R 30^{\circ}}$, (d) $\mathrm{F}_{15 \mathrm{Al} \& \text { Comiss }}^{(\sqrt{3} \times \sqrt{3}) R 30^{\circ}}$ with the atoms which are slightly protruding above the mean surface plane position in dark blue, protruding underneath the mean surface plane position in light blue, and the basic and reconstructed unit cells represented with black lines. Co atoms for the $\mathrm{F}$ termination are presented in red.

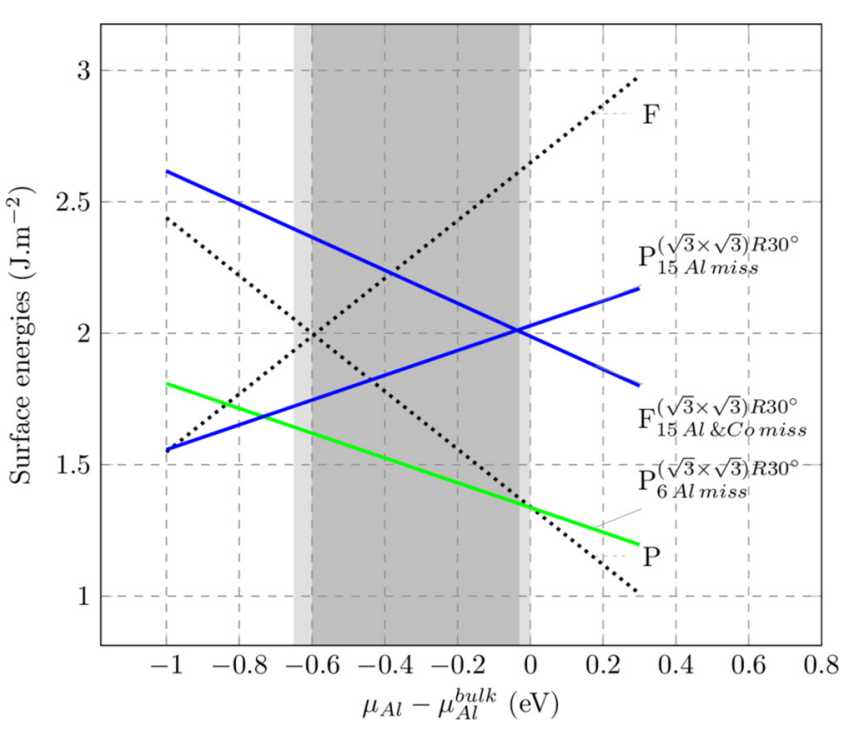

FIG. 12. (Color online) Calculated surface energies for the different models (continuous lines) as well as for nonreconstructed terminations $\mathrm{P}$ and $\mathrm{F}$ (dashed lines), plotted as a function of $\mu_{\mathrm{Al}}-\mu_{\mathrm{Al}}^{\text {bulk }}$

right size and separated by the experimentally observed distance. The first model is a P-terminated surface with $6 \mathrm{Al}_{3}$ atoms missing per reconstructed unit cell [Fig. 11(b)], called $\mathrm{P}_{6 \text { Almiss }}^{(\sqrt{3} \times \sqrt{3}) R 30^{\circ}}$. The 6 removed atoms are taken among the 9 atoms which are slightly protruding above the mean surface plane position. The second model consists of a P-terminated surface with $15 \mathrm{Al}_{3}$ atoms missing per reconstructed unit cell, called $\mathrm{P}_{15 \mathrm{Al} \text { miss }}^{(\sqrt{3} \times \sqrt{3}) R 30^{\circ}}$. All $9 \mathrm{Al}$ atoms slightly protruding above the mean surface plane position and 6 out of $9 \mathrm{Al}$ atoms below the mean position are removed [Fig. 11(c)]. A third possibility consists of an F-terminated surface with $6 \mathrm{Al}_{2}$ atoms and 9 $\mathrm{Co}_{2}$ atoms missing [Fig. 11(d)]. This third model is called $\mathrm{F}_{15 \mathrm{Al} \& \text { Co miss }}^{(\sqrt{3} \times \sqrt{3}) R 0^{\circ}}$

The surface energies of these surface models are displayed in Fig. 12 as a function of $\left(\mu_{\mathrm{Al}}-\mu_{\mathrm{Al}}^{\text {bulk }}\right)$ and compared to complete P- and F-terminated models. From Fig. 12, we conclude that a P-terminated complete surface would be more favorable than an F-terminated surface except for $\left(\mu_{\mathrm{Al}}-\mu_{\mathrm{Al}}^{\text {bulk }}\right)$ $<-0.6 \mathrm{eV}$ (i.e., at the boundary of the allowed range of chemical potential deduced from the simple thermodynamic approach, which is $[-0.65 ; 0] \mathrm{eV})$.

In addition to the previous thermodynamic approach, STM images have been simulated within the Tersoff-Hamann approximation in the constant current mode, where the tunneling current $I$ is proportional to the local density of states at the tip position [54,55]. Simulated STM images are shown in Fig. 13 for models $\mathrm{P}_{6 \mathrm{Almiss}}^{(\sqrt{3} \times \sqrt{3}) R 30^{\circ}}$ and $\mathrm{P}_{15 \mathrm{Almiss}}^{(\sqrt{3} \times \sqrt{3}) R 30^{\circ}}$ and discussed in the following subsection. We notice that in both models, the triangular ensembles observed experimentally by STM are the result of a nonatomic resolution, meaning that the three bright spots forming the triangular motifs are in fact groups of two atoms having different heights with respect to the mean surface plane. The STM images calculated for the $\mathrm{P}_{6 \mathrm{Al} \text { miss }}^{(\sqrt{3} \times \sqrt{3}) R 30^{\circ}}$ show a significant bias dependence. A detailed investigation of 


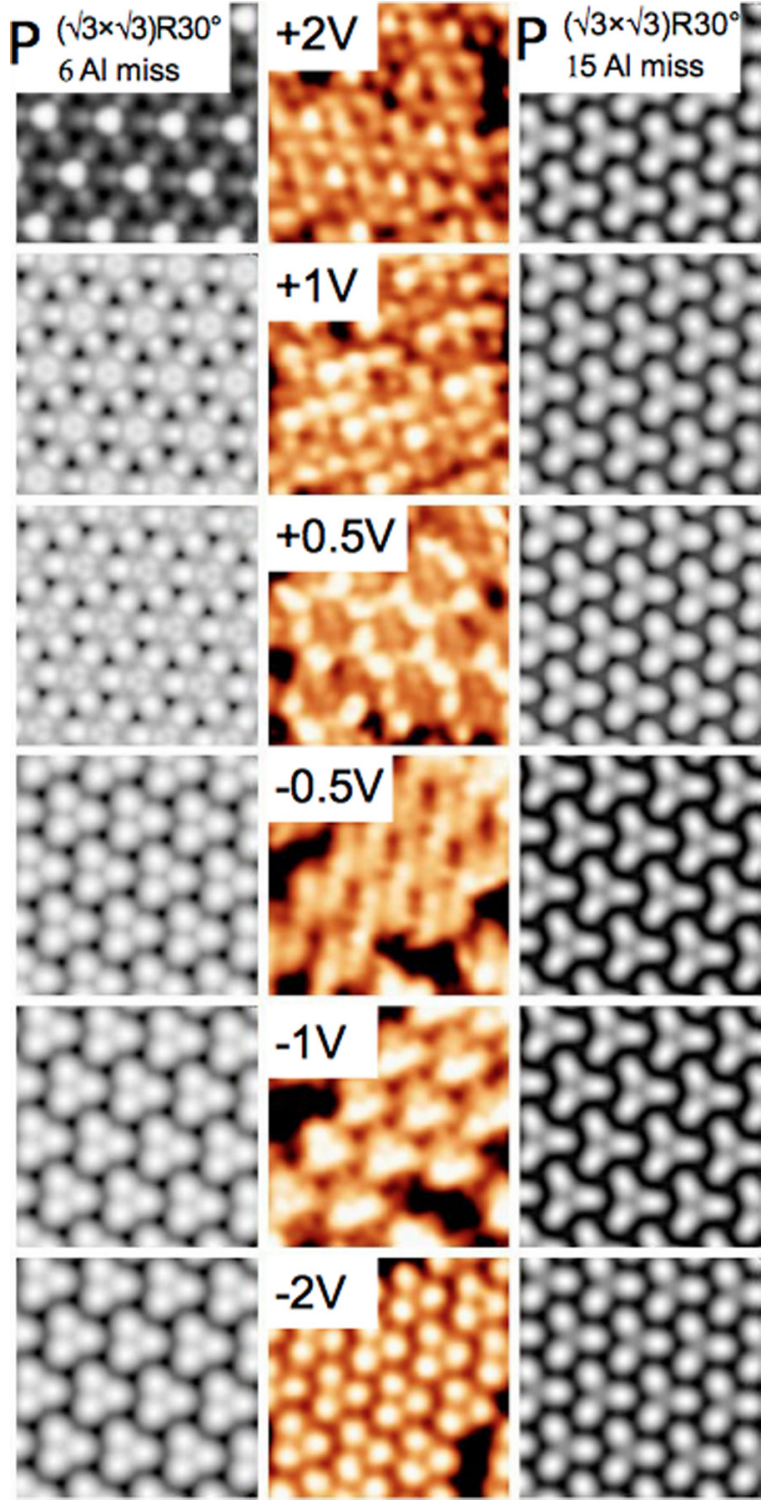

FIG. 13. (Color online) Simulated STM images of the $\mathrm{P}_{6 \mathrm{Almiss}}^{(\sqrt{3} \times \sqrt{3}) R 30^{\circ}}$ model (left), experimental STM images (middle), and simulated STM images of the $\mathrm{P}_{15 \mathrm{Al} \text { miss }}^{(\sqrt{3} \times \sqrt{3}) R 30^{\circ}}$ model (right) for different bias voltages $[+2 \mathrm{~V}$ (top), $+1 \mathrm{~V},+0.5 \mathrm{~V},-0.5 \mathrm{~V},-1 \mathrm{~V},-2 \mathrm{~V}$ (bottom)]. The size of images is $5 \times 5 \mathrm{~nm}^{2}$.

the $\mathrm{Al}$ surface atoms' contribution to the surface DOS shows that the contribution of the $\mathrm{Al}$ surface atoms slightly above the mean position of the surface plane is more asymmetric than the contribution of the other $\mathrm{Al}$ surface atoms. Then, the bias dependence could be attributed to the asymmetry of the contribution of $\mathrm{Al}$ surface atoms slightly protruding above the mean plane position in the $\mathrm{P}_{6 \mathrm{Al} \text { miss }}^{(\sqrt{3} \times \sqrt{3}) R 30^{\circ}}$ model.

The surface electronic structure of the different structural models has also been calculated. In the following, we focus on the one calculated for the $\mathrm{P}_{6 \mathrm{Al} \text { miss }}^{(\sqrt{3} \times \sqrt{3}) R 0^{\circ}}$ surface model (Fig. 14), in comparison with calculated bulk DOS on $\mathrm{P}$ and $\mathrm{F}$ layers. Strong $s p-d$ hybridization leads to sharp peaks in the surface DOS. Although the surface plane contains only $\mathrm{Al}$ atoms, the surface DOS is influenced by subsurface Co atoms. This might
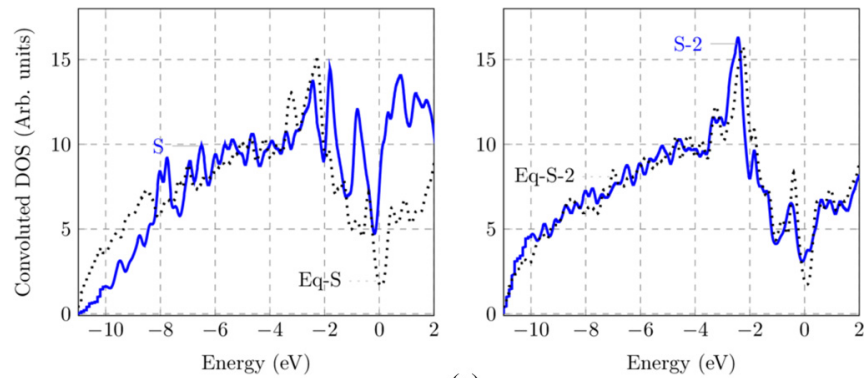

(a)
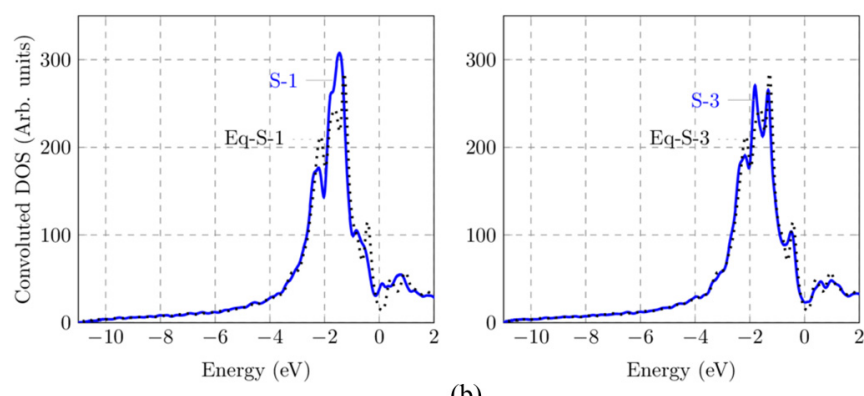

(b)

FIG. 14. (Color online) Calculated DOS for the $\mathrm{P}_{6}^{(\sqrt{3} \times \sqrt{3}) R 30}$ model projected on surface (S) and subsurface planes (S-1) to (S-3) (thick lines). The dotted lines show the bulk DOS of equivalent atoms (Eq-S for the bulk DOS of the equivalent atoms present in the surface layer and Eq-S-1 to Eq-S-3, the bulk DOS of the equivalent atoms present in the corresponding subsurface layers).

influence the surface reactivity and thus could be important for catalytic properties. The effect of the surface is mainly confined to the first two to three topmost layers. A shift of the pseudogap by $0.25 \mathrm{eV}$ towards lower binding energies can be seen for the surface layer, which is decreasing when approaching bulklike layers. The depth of the pseudogap is also reduced in the surface layers compared to the bulk. The density of states at the minimum of the pseudogap increases by $+186 \%$ for the surface layer compared to the density of states of the equivalent atoms in bulk. The S-3 layer shows almost no difference compared to the bulk DOS. The shallower surface pseudogap is in agreement with previous calculations on related Al-T M quasicrystalline surfaces [56].

\section{Combining experimental results and first-principles calculations}

A single termination has been identified experimentally at the $\mathrm{Al}_{5} \mathrm{Co}_{2}(001)$ surface and several models constructed from bulk-terminated surface could account for these observations. From surface energy calculations, the least dense models $\mathrm{F}_{15 \mathrm{Al} \& \text { Comiss }}^{(\sqrt{3} \times \sqrt{3}) R 30^{\circ}}$ and $\mathrm{P}_{15 \mathrm{Al} \text { miss }}^{(\sqrt{3} \times \sqrt{3})}$ are found unstable in the entire range of the chemical potential. Surprisingly, the most stable model is the incomplete $\mathrm{P}_{6 \mathrm{Almiss}}^{(\sqrt{3} \times \sqrt{3}) R 30^{\circ}}$ model rather than the complete $\mathrm{P}$ model and is therefore considered the best candidate to account for the experimental observations. This conclusion still holds when comparing simulated and experimental STM images obtained at different bias voltages. Figure 13 shows such a comparison for the two surface models $\mathrm{P}_{6 \mathrm{Almiss}}^{(\sqrt{3} \times \sqrt{3}) R 30^{\circ}}$ and $\mathrm{P}_{15 \mathrm{Alm}}^{(\sqrt{3} \times \sqrt{3}) R 30^{\circ}}$. The surface model $\mathrm{P}_{15 \mathrm{Al} \text { miss }}^{(\sqrt{3} \times \sqrt{3}) R 30^{\circ}}$ does not show any bias dependency whereas the 


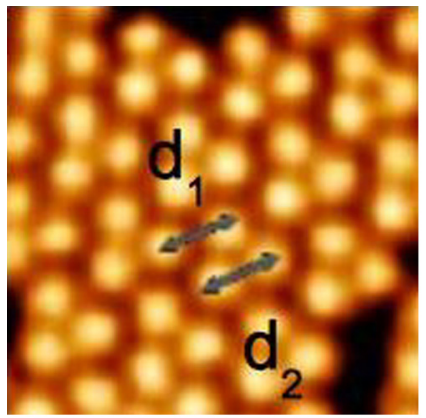

(a)

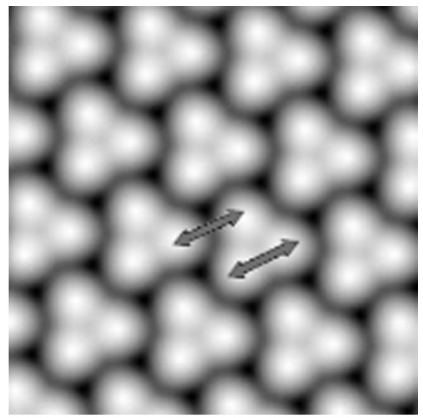

(b)

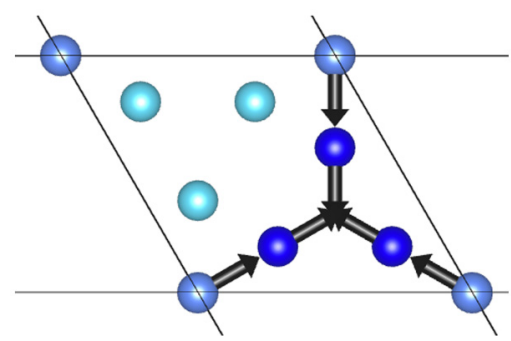

(c)

FIG. 15. (Color online) (a) Experimental and (b) simulated STM images $\left(5 \times 5 \mathrm{~nm}^{2}\right)$ of the surface. The two arrows indicate the two different distances $d_{1}$ and $d_{2}$ (see text). (c) The $\mathrm{P}_{6 \mathrm{Al} \text { miss }}^{(\sqrt{3} \times \sqrt{3}) R 0^{\circ}}$ model where vectors indicate atomic displacements occurring during relaxation.

model $\mathrm{P}_{6 \mathrm{Al} \text { miss }}^{(\sqrt{3} \times \sqrt{3}) R 30^{\circ}}$ correctly reproduces the bias dependency of the experimental data, providing further support to the identification of $\mathrm{P}_{6 \mathrm{Almiss}}^{(\sqrt{3} \times \sqrt{3}) R 30^{\circ}}$ as the most likely $\mathrm{Al}_{5} \mathrm{Co}_{2}(001)$ surface model.

In this paper, all considered slab models have been relaxed (see Sec. II). For the less dense models, surface atomic relaxation occurs not only perpendicularly to the surface plane, but also within the surface plane, as illustrated in Fig. 15 for the $\mathrm{P}_{6 \mathrm{Almiss}}^{(\sqrt{3} \times \sqrt{3}) R 30^{\circ}}$ model. In this case, the triangular atomic ensembles are compressed upon relaxation. This modifies the distances noted $d_{1}$ and $d_{2}$ in Fig. 15(a) (both were equal to the lattice cell parameter before relaxation). The ratio of these two distances $\left(d_{2} / d_{1}\right)$ is calculated for both simulated and experimental STM images and is found to be nearly identical (0.80 and 0.81 , respectively). Once again, the $\mathrm{P}_{6 \mathrm{Almiss}}^{(\sqrt{3} \times \sqrt{3}) R 30^{\circ}}$ model reproduces well the experimental observations.

Electronic-structure calculations with the $\mathrm{P}_{6 \mathrm{Al} \text { miss }}^{(\sqrt{3} \times \sqrt{3}) R 30^{\circ}}$ surface model are also compared with experimental spectroscopic data (Fig. 16). The surface DOS measured by STS shows a minimum at the Fermi level [Fig. 16(a)], in agreement with the calculated DOS. The width of the pseudogap is approximately $1 \mathrm{eV}$ [STS: Fig. 16(a) and DOS: Fig. 14]. The peak observed at $-0.5 \mathrm{eV}$ is also reproduced in the calculation. The measured surface DOS is asymmetric around $E_{F}$, which can be at the origin of the bias dependency of the STM images. This observation is in agreement with the asymmetric contribution of $\mathrm{Al}$ surface atoms to the surface DOS described in the previous subsection. The experimental valence band measured by UPS is shown in Fig. 16(a) and
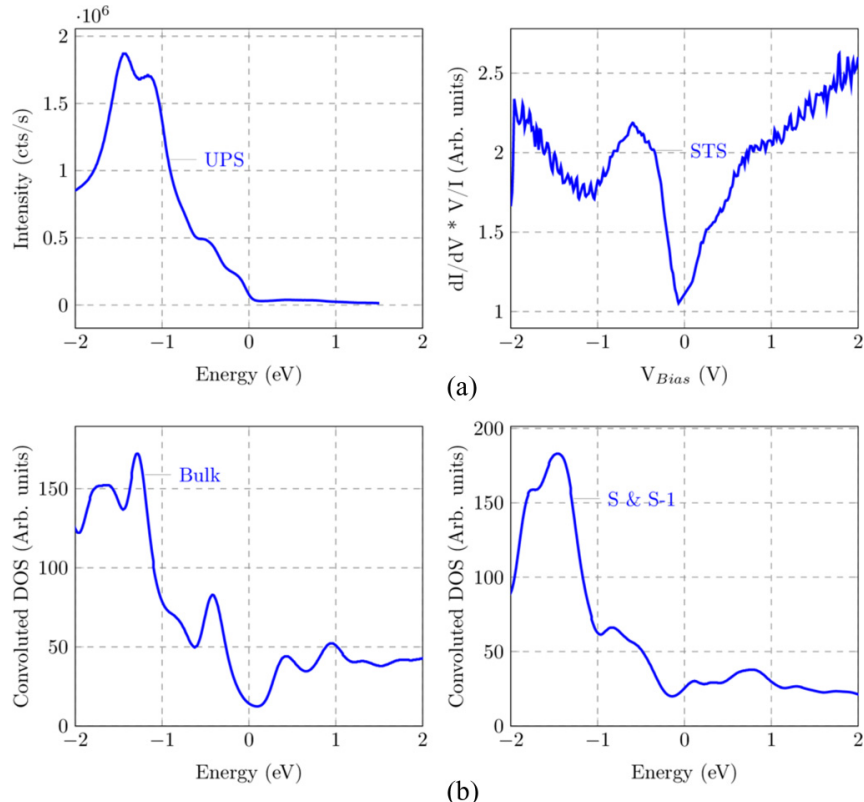

FIG. 16. (Color online) (a) UPS and STS (200 points from $-2 \mathrm{~V}$ to $+2 \mathrm{~V}, 0.18 \mathrm{nA}, 0$ to $3.3 \mathrm{nA}$ range, grid $10 \times 10$, on a $50 \times 50 \mathrm{~nm}^{2}$ surface) data, (b) total bulk convoluted DOS and $\mathrm{S}+$ S-1 layers convoluted DOS.

is in agreement with the calculation by considering the first two surface layers [Fig. 16(b)]. A slight shift in energy can be observed, becoming larger with decreasing energy. This is a known consequence of not considering the quasiparticle self-energy from electron-electron interactions when using the DFT-GGA approximation. The width of the $d$ band obtained by UPS is also lower than the calculated one [57].

\section{Other structures of the $\mathrm{Al}_{5} \mathrm{Co}_{2}$ (001) surface}

In this section, we present additional results obtained by preparing the surface to either lower or higher annealing temperatures than the one producing the $(\sqrt{3} \times \sqrt{3}) R 30^{\circ}$ reconstruction $(973 \mathrm{~K})$.

Low-temperature phase. We describe here the occurrence of a $(2 \times 2)$ reconstruction observed experimentally after annealing the surface at low temperature $(823 \mathrm{~K})$. A typical LEED pattern of the surface prepared in this low-temperature regime is shown in Fig. 17(a). Here again the sharpest diffraction spots correspond to the hexagonal unit mesh with lattice parameter equal to $7.6 \pm 0.4 \AA$. The most diffuse diffraction spots forming a hexagonal honeycomb surrounding each primitive spot characteristic of the $(\sqrt{3} \times \sqrt{3}) R 30^{\circ}$ reconstruction are not observed anymore. Instead, additional diffuse spots on a $(2 \times 2)$ mesh can be seen, with parameter estimated at $15.6 \pm 0.4 \AA$. Some streaks extending along lines connecting the primitive spots are also observed. The spots of the $(2 \times 2)$ reconstruction are weaker than those of the $(\sqrt{3} \times \sqrt{3}) R 30^{\circ}$, indicating an even shorter coherence length.

The short coherence length is also obvious in STM images of the surface, as the one shown in Fig. 17(b). The same triangular ensembles as for the $(\sqrt{3} \times \sqrt{3}) R 30^{\circ}$ phase are observed but they are now preferentially located at the nodes of a $(2 \times 2)$ lattice. The density of triangular ensembles is 


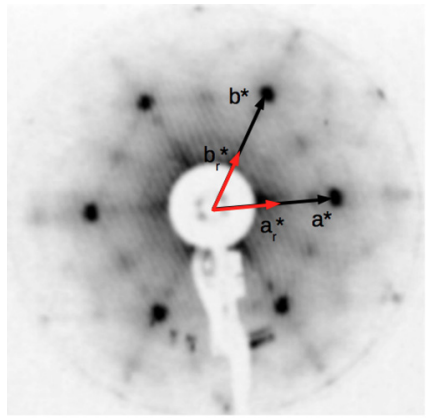

(a)

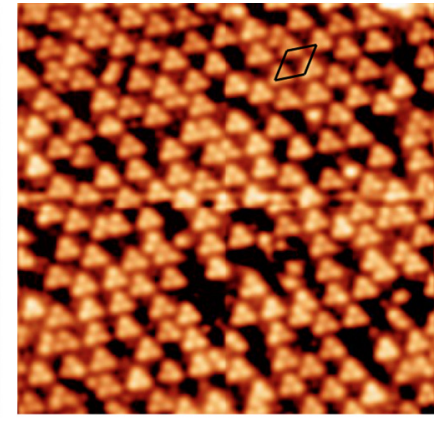

(b)

FIG. 17. (Color online) (a) LEED pattern at $19 \mathrm{eV}$ of the $\mathrm{Al}_{5} \mathrm{Co}_{2}(001)$ surface prepared at low temperature ( $\left.823 \mathrm{~K}\right)$, showing the $(2 \times 2)$ reconstruction. (b) STM image of the $\mathrm{Al}_{5} \mathrm{Co}_{2}(001)$ surface after annealing at $823 \mathrm{~K}\left[20 \times 20 \mathrm{~nm}^{2},-2 \mathrm{~V}\right.$ bias voltage, $0.12 \mathrm{nA}$, with $(2 \times 2)$ reconstructed unit cell showed with black lines].

lower than for the $(\sqrt{3} \times \sqrt{3}) R 30^{\circ}$ phase by a factor of $\frac{3}{4}$. The long-range order of the $(2 \times 2)$ lattice is rather limited, in agreement with the LEED pattern.

Two models can be elaborated to account for the observed $(2 \times 2)$ reconstruction. The first model is a $\mathrm{P}$ termination with nine $\mathrm{Al}$ atoms missing per reconstructed unit cell [Fig. 18(a)], called $\mathrm{P}_{9 \mathrm{Almiss}}^{(2 \times 2)}$. The nine missing atoms correspond to three sets of $\mathrm{Al}_{3}$ atoms out of the four contained in a $(2 \times 2)$ unit cell. The second model is a $\mathrm{P}$ termination with $10 \mathrm{Al}$ atoms missing per reconstructed unit cell, called $\mathrm{P}_{10 \mathrm{Almiss}}^{(2 \times 2)}$ [Fig. 18(b)]. This model has the same 9 atoms missing than the first model and an additional $\mathrm{Al}_{1}$ atom missing. This $\mathrm{Al}_{1}$ atom is not part of any triangular ensembles and might not be distinguished in experimental STM images. The calculated surface energies for these two models indicate that the $\mathrm{P}_{10 \mathrm{Almiss}}^{(2 \times 2)}$ model is slightly more stable than $\mathrm{P}_{9 \mathrm{Almiss}}^{(2 \times 2)}$ in the appropriate range of the chemical potential. However, the energy difference between the two models is very small.

In order to differentiate between the two, bias-dependent STM images have been calculated and compared to experimental ones. The results are shown in Fig. 19. While at positive bias the two models provide a reasonable match with the experiment, the extra $\mathrm{Al}_{1}$ atom in the $\mathrm{P}_{9 \mathrm{Al} \text { miss }}^{(2 \times 2)}$ clearly does not appear in the experimental STM images at negative bias. Therefore, both surface energies and simulated STM images point toward the $\mathrm{P}_{10 \mathrm{Almiss}}^{(2 \times 2)}$ model.

Finally, we mention that the two types of reconstruction $\left[(2 \times 2)\right.$ and $\left.(\sqrt{3} \times \sqrt{3}) R 30^{\circ}\right]$ can coexist upon annealing

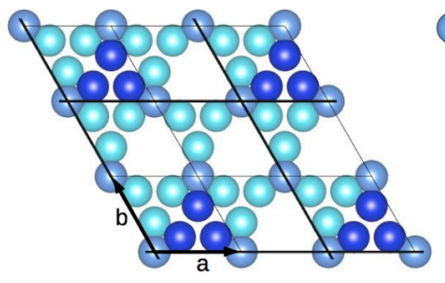

(a)

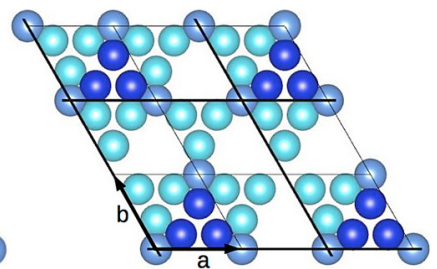

(b)

FIG. 18. (Color online) (a) Model $\mathrm{P}_{9 \mathrm{Almiss}}^{(2 \times 2)}$ and (b) model $\mathrm{P}_{10 \mathrm{Almiss}}^{(2 \times 2)}$.

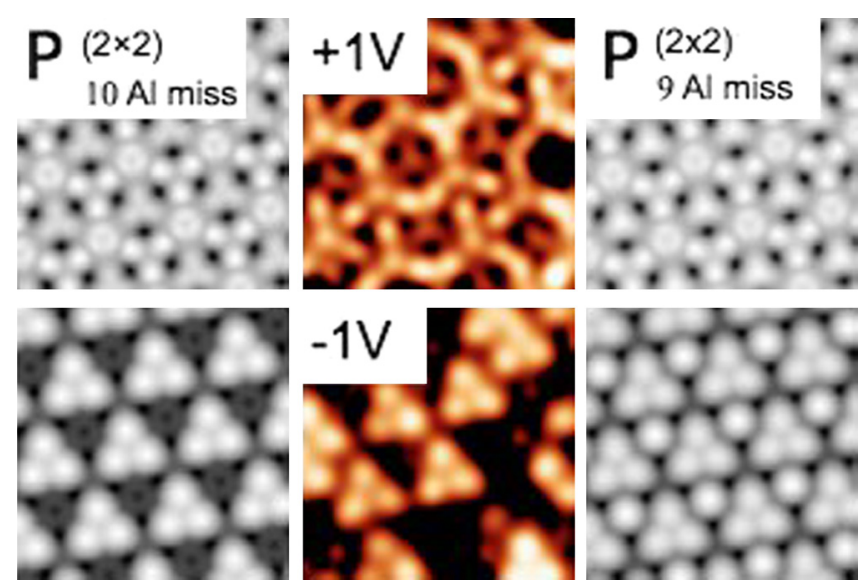

FIG. 19. (Color online) Simulated STM images of $\mathrm{P}_{10 \mathrm{Almiss}}^{(2 \times 2)}$ (left), experimental STM images (middle), simulated STM images of $\mathrm{P}_{9 \mathrm{Al} \text { miss }}^{(2 \times 2)}$ (right), for different bias voltages $(+1 \mathrm{~V}$ and $-1 \mathrm{~V})$. The size of images is $5 \times 5 \mathrm{~nm}^{2}$.

the surface at intermediate temperature, between 823 and 973 $\mathrm{K}$. Thus, there is no sharp transition between the two phases.

High-temperature phase. We now present the surface structure of the (001) surface prepared by high annealing temperature $(1180 \mathrm{~K})$. After such surface preparation, the LEED pattern indicated a well-ordered $(1 \times 1)$ structure having sixfold rotational symmetry, as shown in Fig. 20. No traces of the reconstructions are left. A LEED-IV analysis was performed in order to determine the surface structure in this case. The layers in $\mathrm{Al}_{5} \mathrm{Co}_{2}$ are stacked in a P1F1P2F2 arrangement such that $\mathrm{P} 1$ and $\mathrm{P} 2$, or $\mathrm{F} 1$ and $\mathrm{F} 2$, are related by a rotation of $180^{\circ}$ (see Fig. 1). Each of the two puckered terminations would produce a diffraction pattern having threefold symmetry, and a surface with half of each termination $(\mathrm{P} 1+\mathrm{P} 2$ or $\mathrm{F} 1+\mathrm{F} 2)$ would produce a diffraction pattern with sixfold symmetry, as observed in this experiment. Therefore, the two terminations were averaged in the intensity analysis. The first part of the analysis treated the coordinates of the top six layers of the crystal as adjustable parameters, and relaxed the vertical components of all atoms in the top six layers. The $R$ factors after the first run were 0.54 for the $\mathrm{P}$ terminations and 0.56 for the $\mathrm{F}$ terminations. We then tested models with incomplete top layers that are consistent with a $(1 \times 1)$ structure, and the best of these gave $R>0.56$ for the $\mathrm{F}$ terminations and $R=0.41$ for the $\mathrm{P}$ terminations. The best $\mathrm{P}$ termination was the so-called $\mathrm{P}_{3 \mathrm{Almiss}}^{(1 \times 1)}$ model.
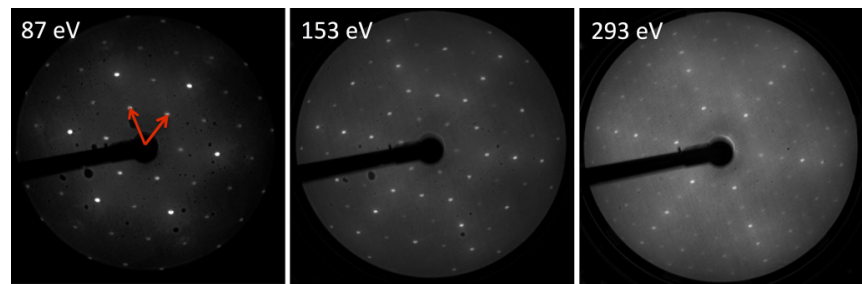

FIG. 20. (Color online) LEED patterns of $\mathrm{Al}_{5} \mathrm{Co}_{2}(001)$ after annealing $(T=1180 \mathrm{~K}$ for $1 \mathrm{~h}$ ), recorded at $T=134 \mathrm{~K}$, for three different incident beam energies. The reciprocal unit-cell vectors are shown in the $87 \mathrm{eV}$ pattern. 


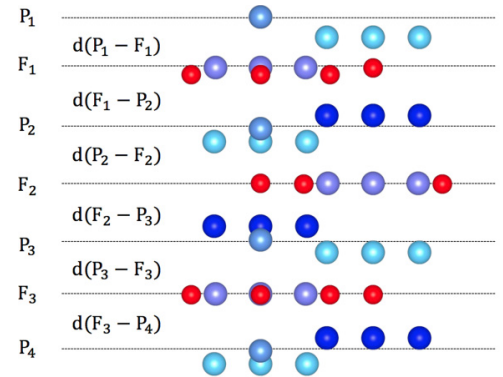

\begin{tabular}{|c|c|c|}
\hline Parameter & $(\AA)$ & $\%$ \\
\hline $\mathrm{d}(\mathrm{P} 1-\mathrm{F} 1)$ & $1.47 \pm 0.06$ & -10.91 \\
\hline $\mathrm{d}(\mathrm{F} 1-\mathrm{P} 2)$ & $1.99 \pm 0.05$ & 5.85 \\
\hline $\mathrm{d}(\mathrm{P} 2-\mathrm{F} 2)$ & $1.87 \pm 0.04$ & -0.53 \\
\hline $\mathrm{d}(\mathrm{F} 2-\mathrm{P} 3)$ & $1.91 \pm 0.04$ & 1.60 \\
\hline $\mathrm{d}(\mathrm{P} 3-\mathrm{F} 3)$ & $1.87 \pm 0.05$ & -0.53 \\
\hline $\mathrm{d}(\mathrm{F} 3-\mathrm{F} 4)$ & $1.93 \pm 0.07$ & 2.66 \\
\hline$\Delta \mathrm{P} 1$ & 0.49 & \\
\hline$\Delta \mathrm{F} 1$ & 0.14 & \\
\hline$\Delta \mathrm{P} 2$ & 0.45 & \\
\hline$\Delta \mathrm{F} 2$ & 0.01 & \\
\hline$\Delta \mathrm{P} 3$ & 0.45 & \\
\hline$\Delta \mathrm{F} 3$ & 0.02 & \\
\hline
\end{tabular}

FIG. 21. (Color online) Side view of the relaxations of the surface layers. The blue spheres are $\mathrm{Al}$ and the red spheres are Co. $d$ is the interlayer spacing, $\Delta$ is the average pucker in the surface layers, and the percent deviation from the bulk spacings is also given. The bulk interlayer spacing is $1.88 \AA$ and the average pucker of the bulk P layers is $0.46 \AA$.

This model has all of its $\mathrm{Al}_{3}$ atoms that protrude above the mean surface plane position removed. According to the DFT calculations, it would have the lowest surface energy among all considered models in the Co-rich part of the chemical potential $\left[\left(\mu_{\mathrm{Al}}-\mu_{\mathrm{Al}}^{\text {bulk }}\right)<-0.45 \mathrm{eV}\right]$. This model leads to an $R$ factor after the first run of 0.41 , allowing us to rule out other models.

The $\mathrm{P}_{3 \mathrm{Almiss}}^{(1 \times 1)}$ termination was then optimized along with the Debye temperatures, which are parameters related to the atomic vibration amplitudes in the calculation. The structural results of the analysis are given in Fig. 21, and the best-fit calculated curves are shown with the experimental curves in Fig. 22. The optimization of the vibration amplitudes resulted in 0.21 and $0.16 \AA$, respectively, for the surface layers of $\mathrm{Al}$ and $\mathrm{Co}$, and 0.11 and $0.07 \AA$ for the bulk layers of $\mathrm{Al}$ and Co. The total $R$ factor achieved is 0.32 . This dynamical LEED analysis demonstrates that annealing the (001) surface at high temperature leads to complete desorption of the $\mathrm{Al}_{3}$ sets of atoms resulting from surface truncated clusters, in agreement with calculated surface energies for the Co-rich range of the chemical potential. A complementary STM study

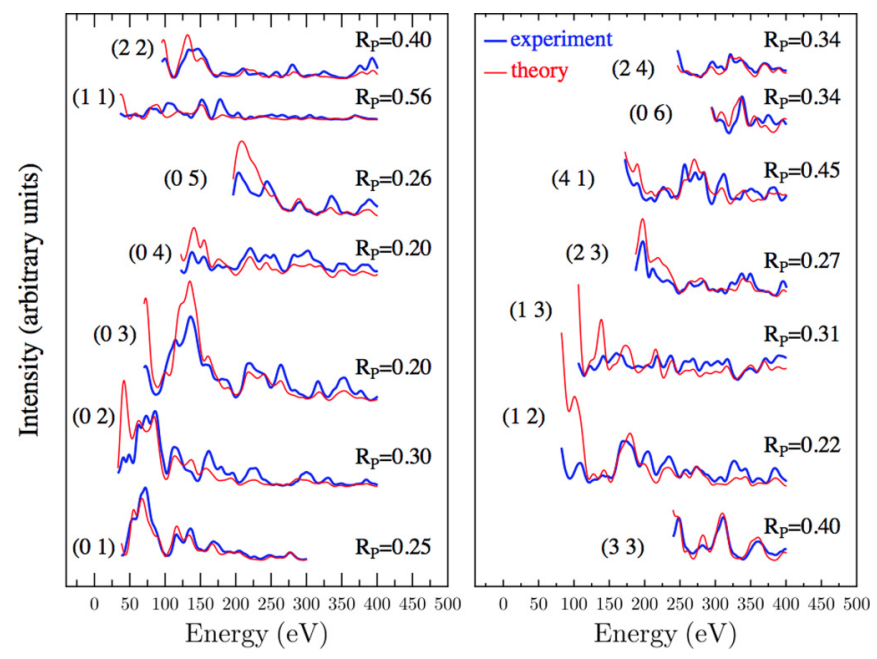

FIG. 22. (Color online) Comparison of experimental and theoretical LEED I(E) curves for 14 independent beams. The individual Pendry factors (Rp) are shown. The total $R$ factor is 0.32 .
TABLE III. Interlayer spacing $d$ relaxation (compared to bulk interlayer spacing $d_{0}$ ) in different models (in \%).

\begin{tabular}{lc}
\hline \hline Models & $\left(d-d_{0}\right) / d_{0}$ \\
\hline $\mathrm{P}_{6 \mathrm{Al} \text { miss }}^{(\sqrt{3} \times \sqrt{3}) R 30^{\circ}}$ & -6.3 \\
$\mathrm{P}_{10 \mathrm{Al} \text { miss }}^{(2 \times 2)}$ & -9.2 \\
$\mathrm{P}_{3 \mathrm{Al} \text { miss }}^{(1 \times 1)}$ & -9.9 \\
\hline \hline
\end{tabular}

of the surface in the same temperature regime is consistent with this result, although some $\mathrm{Al}_{3}$ triangular sets still remain at the surface but with a low density and a random distribution.

\section{Discussion}

The combination of both experimental and theoretical approaches is powerful to draw a clear picture of the thermodynamic, electronic, and vibrational bulk properties. It also provides a comprehensive description of the $\mathrm{Al}_{5} \mathrm{Co}_{2}(001)$ surface atomic and electronic structures. DFT calculations not only help to determine the surface structure, but also provide an explanation of the phenomenon in relation to the electronic structure of the crystal. For the high-temperature prepared surface, LEED-IV calculations give results in perfect agreement with STM/LEED experiments and $a b$ initio calculations. For example, the interlayer spacing relaxation of the topmost surface layer $\left[d\left(P_{1}-F_{1}\right)\right]$ obtained by LEED-IV calculations for the $\mathrm{P}_{3 \mathrm{Almiss}}^{(1 \times 1)}$ model is $-10.9 \%$, compared to DFT calculations which give a value of $-9.9 \%$. Regarding interlayer spacings, Table III shows the topmost interlayer spacing for the different surface termination observed at different temperatures $\left(\mathrm{P}_{10 \mathrm{Almiss}}^{(2 \times 2)}\right.$ at $823 \mathrm{~K}, \mathrm{P}_{6 \mathrm{Al} \text { miss }}^{(\sqrt{3} \times \sqrt{3}) R 30^{\circ}}$ at 973 $\left.\mathrm{K}, \mathrm{P}_{3 \mathrm{Almiss}}^{(1 \times 1)} 1180 \mathrm{~K}\right)$. With decreasing density of triangularshaped ensembles, the relaxation is increasing (the missing atomic ensembles allow the remaining atoms to move more and thus relax towards the bulk).

In the following, the interplay between the $\mathrm{Al}_{5} \mathrm{Co}_{2}$ threedimensional structure and the $\mathrm{Al}_{5} \mathrm{Co}_{2}(001)$ surface is investigated carefully. The case of related Al-Co complex metallic alloys is also raised.

\section{Chemical bonds and the origin of the surface reconstruction}

The surface structure described previously can be understood in the light of the chemical bondings in $\mathrm{Al}_{5} \mathrm{Co}_{2}$. Indeed, the group of three $\mathrm{Al}_{3}$ atoms in the $\left(\mathrm{Co}_{1}\right)\left(\mathrm{Al}_{3}\right)_{6}$ clusters (see Fig. 1) correspond to the triplets of atoms observed in STM images. They also correspond to triplets of atoms that need to be removed from the P layer in order to form the $\mathrm{P}_{6 \mathrm{Almiss}}^{(\sqrt{3} \times \sqrt{3}) R 30^{\circ}}$ model of the reconstructed surface. The reconstruction results from the fact that only 1 out of 3 sets of $\mathrm{Al}_{3}$ atoms which are slightly protruding above the mean surface plane position remains at the surface in a (mostly) ordered way. This mechanism leads to the presence of domains which can be observed in STM images as illustrated in Fig. 23(a). Each domain presents the same reconstruction and atomic arrangement, but are shifted from each other by one third of the diagonal of the reconstructed surface unit cell. The 


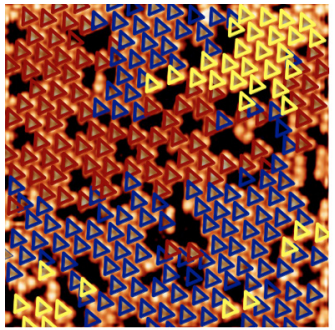

(a)

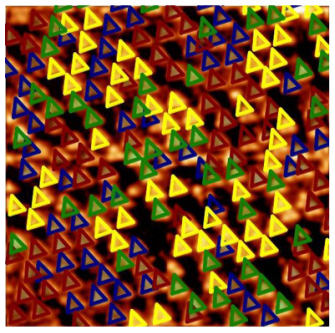

(c)

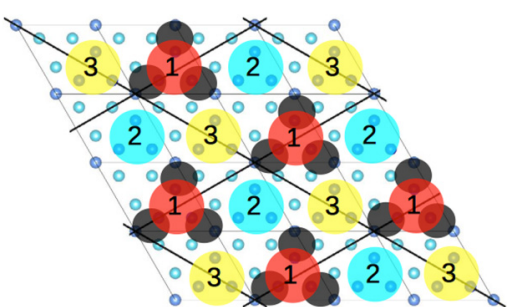

(b)

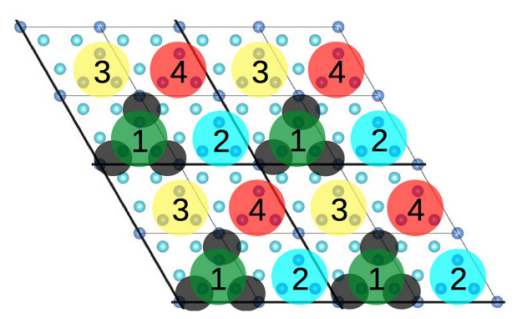

(d)
FIG. 23. (Color online) (a) Domains highlighted on a $20 \times$ $20 \mathrm{~nm}^{2}$ experimental STM image obtained for the surface prepared at $973 \mathrm{~K}$, (b) schematic illustrating the three possibilities to form the reconstruction $(973 \mathrm{~K})$, (c) domains highlighted on a $20 \times 20 \mathrm{~nm}^{2}$ experimental STM image obtained for the surface prepared at $823 \mathrm{~K}$, (d) schematic illustrating the four possibilities to obtain the reconstruction $(823 \mathrm{~K})$.

domains occur because there are three different possibilities to obtain the reconstruction, i.e., to remove two out of the three equivalent sets of atoms. Figure 23(b) illustrates the three possibilities. The diffuse intensity of the reconstruction LEED pattern can be explained by the existence of these antiphase domains. Figure 23(c) shows the same mechanism for the $(2 \times 2)$ reconstruction observed on the surface prepared at low temperature $(823 \mathrm{~K})$, where 1 out of 4 triplets which are slightly protruding above the mean surface plane position remains. In this case, there are four possibilities to remove the $\mathrm{Al}_{3}$ sets in order to obtain the reconstruction. This is sketched in Fig. 23(d) and the domains are color coded in the STM image. The size of the domains is much smaller than those observed for the higher-temperature $(\sqrt{3} \times \sqrt{3}) R 30^{\circ}$ phase and this is also in agreement with the more diffused reconstruction spots on the corresponding LEED pattern. For the $\mathrm{P}_{3 \mathrm{Almiss}}^{(1 \times 1)}$ model, all $\mathrm{Al}_{3}$ triplets which are slightly protruding above the mean surface plane position are removed, meaning that the remaining surface contains no truncated $\left(\mathrm{Co}_{1}\right)\left(\mathrm{Al}_{3}\right)_{6}$ clusters.

To gain further understanding, we have calculated the surface energies of additional models characterized by different fraction of missing triplets of $\mathrm{Al}_{3}$ atoms, from $0 \%$ to $100 \%$. These models and the models already used to identify the surface at different temperatures are listed in Table IV. The surface energies of the different models are plotted in Fig. 24 as a function of $\left(\mu_{\mathrm{Al}}-\mu_{\mathrm{Al}}^{\text {bulk}}\right)$. The results show that the

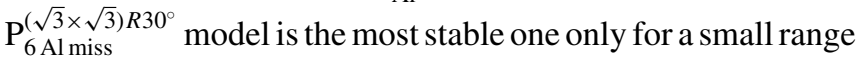
of the chemical potential (in the Al-rich part). In the Co-rich part $\left[\left(\mu_{\mathrm{Al}}-\mu_{\mathrm{Al}}^{\text {bulk }}\right)<-0.6 \mathrm{eV}\right]$, the $\mathrm{P}_{3 \mathrm{Al} \text { miss }}^{(1 \times 1)}$ model would have an even lower surface energy. The surface energy of the $\mathrm{P}_{10 \mathrm{Al} \text { miss }}^{(2 \times 2)}$ model is very close to that of the $\mathrm{P}_{6 \mathrm{Almiss}}^{(\sqrt{3} \times \sqrt{3}) R 30^{\circ}}$ model.
TABLE IV. Calculated forces (modulus in $\mathrm{eV} / \AA$ ) acting on $\mathrm{Al}_{3}$ atoms which are slightly protruding above the mean surface plane position before relaxation for different surface models (for $\mathrm{P}_{3 \mathrm{Almiss}}^{(1 \times 1)}$ with no $\mathrm{Al}_{3}$ atoms left and $\mathrm{P}_{6 \mathrm{Al} \text { miss }}^{(\sqrt{3} \times \sqrt{3}) R 30^{\circ}}$, the indicated forces in parentheses are the highest ones acting on atoms in the topmost surface layer). Both the calculated forces in plane $(\|)$ and perpendicular to the surface $(\perp)$ are mentioned in the table.

\begin{tabular}{|c|c|c|c|}
\hline \multirow[t]{2}{*}{ Models } & \multirow{2}{*}{$\begin{array}{c}\text { Missing } \\
\mathrm{Al}_{3} \text { ensembles }\end{array}$} & \multicolumn{2}{|c|}{ Forces on $\mathrm{Al}_{3}$ ensembles } \\
\hline & & $\|$ & $\perp$ \\
\hline $\mathrm{P}_{\text {complete }}$ & $0 \%$ & 1.47 & 0.02 \\
\hline $\begin{array}{l}\mathrm{P}_{3 \mathrm{Almiss}}^{(\sqrt{3} \times \sqrt{3}) R 30^{\circ}}\end{array}$ & $33 \%$ & 1.19 & 0.02 \\
\hline $\begin{array}{l}\mathrm{P}_{6 \text { Al miss }}^{(\sqrt{3} \times \sqrt{3}) R 30^{\circ}}\end{array}$ & $66 \%$ & $\underline{0.88}(0.97)$ & 0.06 \\
\hline $\mathrm{P}_{\text {random }}$ & $66 \%$ & 1.24 & 0.07 \\
\hline $\mathrm{P}_{10 \mathrm{Al} \text { miss }}^{(2 \times 2)}$ & $75 \%$ & 0.92 & 0.02 \\
\hline $\mathrm{P}_{3 \mathrm{Al} \text { miss }}^{(1 \times 1)}$ & $100 \%$ & $-(1.02)$ & - \\
\hline
\end{tabular}

Finally, we have calculated the forces acting on the $\mathrm{Al}_{3}$ atomic ensembles for the different models before ionic relaxation. The results are presented in Table IV. The main forces are contained within the surface plane. The forces acting in the direction normal to the surface are negligible (an order of magnitude lower). It is remarkable that the forces acting on the $\mathrm{Al}_{3}$ atomic ensembles are the smallest for the $\mathrm{P}_{6 \mathrm{Almiss}}^{(\sqrt{3} \times \sqrt{3}) R 30^{\circ}}$ model. Note also that the model called $\mathrm{P}_{\text {random }}$ which shows no local ordering indicates much higher forces despite the fact that it contains the same amount of missing

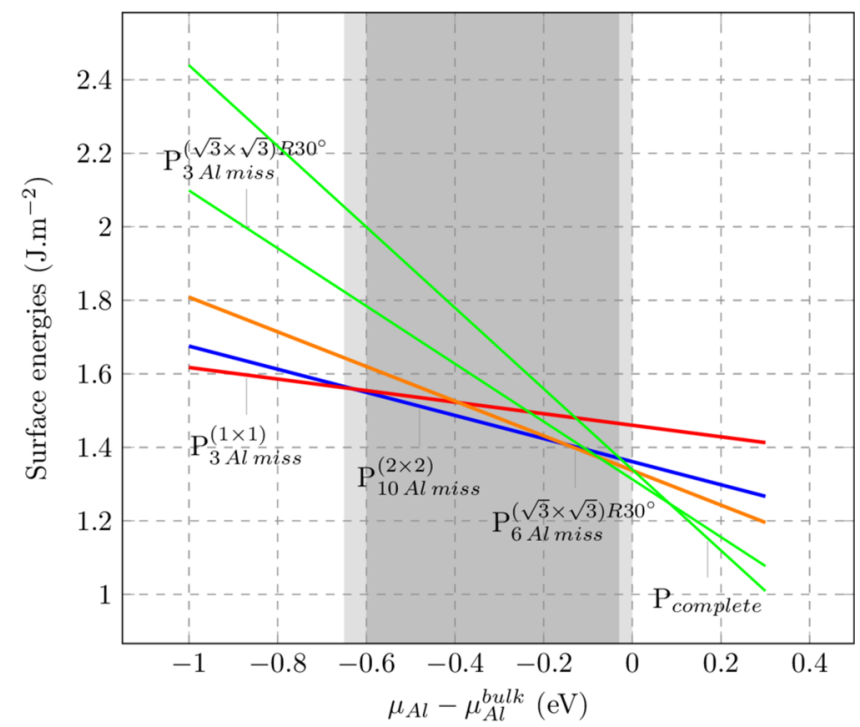

FIG. 24. (Color online) Calculated surface energies for the different models described in Tab. IV plotted as a function of $\mu_{\mathrm{Al}}-\mu_{\mathrm{Al}}^{\text {bulk }}$ (surface energy for the $\mathrm{P}_{\text {random }}$ model has not been calculated, because of its size ( $>600$ atoms) needed to simulate the disorder). $\mathrm{P}_{3 \text { Almiss }}^{(1 \times 1)}$ is in red(observed experimentally at high temperature $1180 \mathrm{~K}), \mathrm{P}_{10 \mathrm{Al} \text { miss }}^{(2 \times 1 \mathrm{~s}}$ is in blue (observed experimentally at low temperature $823 \mathrm{~K}$ ), $\mathrm{P}_{6 \mathrm{Al} \text { miss }}^{(\sqrt{3} \times \sqrt{3}) R 30^{\circ}}$ is in orange (seen for the surface prepared at $973 \mathrm{~K}$ ) and $\mathrm{P}_{\text {complete }}, \mathrm{P}_{3 \text { Al miss }}^{(\sqrt{3} \times \sqrt{3}) R 0^{\circ}}$ for comparison purposes are in green (not observed experimentally). 


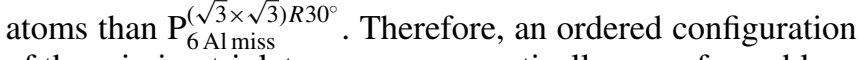
of the missing triplets appears energetically more favorable.

\section{Surface structures of related Al-Co complex metallic alloys}

The most stable surface termination corresponds to puckered layers where $\frac{2}{3}$ of $\mathrm{Al}_{3}$ sets resulting from truncated $\left(\mathrm{Co}_{1}\right)\left(\mathrm{Al}_{3}\right)_{6}$ clusters have desorbed. This highlights the effect of the three-dimensional clusters on the surface structure of $\mathrm{Al}_{5} \mathrm{Co}_{2}$ phase. Other intermetallics also present a cluster substructure, for example, the decagonal approximants $\mathrm{Al}_{13} T M_{4}$ ( $T M=\mathrm{Co}, \mathrm{Fe}$ ). These compounds have been described as cage compounds containing a strong $T M$-Al- $T M$ molecular group [58,59]. The pseudotenfold terminating plane of $\mathrm{Al}_{13} \mathrm{Co}_{4}$ is dense, almost flat, and Al-rich [60,61], while the pseudotenfold terminating plane of $\mathrm{Al}_{13} \mathrm{Fe}_{4}$ has been found to be highly corrugated [6]. In these $\mathrm{Al}_{13} \mathrm{TM}_{4}$ compounds, the strength of the $T M$-Al- $T M$ bonds within the encapsulated molecular group has been calculated to be $0.31 \mathrm{eV}$ in the case of $\mathrm{Co}-\mathrm{Al}-\mathrm{Co}$ and $0.66 \mathrm{eV}$ for Fe-Al-Fe. One can then understand the pseudotenfold surface structure by a preservation of the cluster substructure at the surface in the case of $\mathrm{Al}_{13} \mathrm{Fe}_{4}$ (no $\mathrm{Fe}-\mathrm{Al}-\mathrm{Fe}$ bonds are cut at the surface) but not in the case of $\mathrm{Al}_{13} \mathrm{Co}_{4}$ (half of the Co-Al-Co bonds are cut at the surface), in part due to a stronger $T M-\mathrm{Al}-T M$ bond strength in $\mathrm{Al}_{13} \mathrm{Fe}_{4}$ than in $\mathrm{Al}_{13} \mathrm{Co}_{4}$. In $\mathrm{Al}_{5} \mathrm{Co}_{2}$, the strongest $\mathrm{Al}-\mathrm{Co}$ bonds present an intermediate strength $(0.49 \mathrm{eV})$ compared to the Co-Al-Co and $\mathrm{Fe}-\mathrm{Al}-\mathrm{Fe}$ ones. It might explain why only a fraction of clusters remain intact at the surface, at least at intermediate temperature.

\section{SUMMARY AND CONCLUSIONS}

The $\mathrm{Al}_{5} \mathrm{Co}_{2}$ compound is a small size approximant of decagonal quasicrystalline phases containing atomic motifs. In order to study the interplay between these bulk atomic motifs and the surface structure, a single crystal of this phase has been grown using the Czochralski technique. Its (001) surface has been investigated thoroughly by both experimental methods and DFT calculations. The constitutional defects have been calculated to be Co antisites for Co-rich phases and Co vacancies for Al-rich phases. Calculated defect concentrations are in agreement with the small compositional range experimentally determined for $\mathrm{Al}_{5} \mathrm{Co}_{2}$. The bulk phonon DOS has been computed and the sound velocities have been deduced from the acoustic branches. The calculated Debye temperature (550 $\mathrm{K})$ was found in agreement with the experimental one deduced from the specific heat measured at low temperature $(600 \mathrm{~K})$. The calculated $C_{p}$ is in perfect agreement with the experiment.
From the electronic contribution to the specific heat, a value of $n\left(E_{F}\right)=0.14$ states/eV atom is deduced, consistent with our DFT calculations $\left[n\left(E_{F}\right)=0.12\right.$ states/(eV atom $\left.)\right]$ and the existence of a deep pseudogap at $E_{F}$ in this compound.

The structure of the (001) surface was found to depend on the annealing temperature. The LEED pattern obtained after annealing the surface at $973 \mathrm{~K}$ showed a $(\sqrt{3} \times \sqrt{3}) R 30^{\circ}$ reconstruction. A diffuse $(2 \times 2)$ LEED pattern was observed at lower annealing temperature $(823 \mathrm{~K})$ while a $(1 \times 1)$ pattern appeared at higher temperature $(1180 \mathrm{~K})$. In the case of the $(\sqrt{3} \times \sqrt{3}) R 30^{\circ}$ reconstruction, we found that the $\mathrm{P}_{6 \mathrm{Al} \text { miss }}^{(\sqrt{3} \times \sqrt{3}) R 30^{\circ}}$ model, where the surface terminates at puckered layers with 6 out of $9 \mathrm{Al}_{3}$ atoms per reconstructed unit cell are missing, is the only model matching with all experimental observations and theoretical results. It can be understood by removing two thirds of the surface $\mathrm{Al}_{3}$ groups belonging to the three-dimensional $\left(\mathrm{Co}_{1}\right)\left(\mathrm{Al}_{3}\right)_{6}$ bulk cluster, in an ordered way. According to surface energy calculations, the $\mathrm{P}_{6 \mathrm{Almiss}}^{(\sqrt{3} \times \sqrt{3}) R 30^{\circ}}$ model is the most stable one only for the Al-rich part of the chemical potential, while for the Co-rich part a $\mathrm{P}_{3 \mathrm{Al} \text { miss }}^{(1 \times 1)}$ model is predicted to be even more stable and corresponds to the $(1 \times 1)$ phase observed at high annealing temperature. For intermediate chemical potentials, the $(2 \times 2)$ reconstruction obtained by removing $75 \%$ of $\mathrm{Al}_{3}$ sets is stable and corresponds to the $(2 \times 2)$ phase observed at low annealing temperature.

Finally, electron DOS have been calculated for the $\mathrm{P}_{6 \mathrm{Almiss}}^{(\sqrt{3} \times \sqrt{3}) R 30^{\circ}}$ model and compared to experimental data. It shows the presence of a reduced pseudogap at the Fermi level and $s p$ - $d$ hybridization between the topmost Al pure layer and subsurface Co atoms present in the F layer underneath. This is an important feature which could affect the catalytic performances of this surface. Further development of this work will investigate the surface chemical reactivity with respect to heterogeneous hydrogenation reactions.

\section{ACKNOWLEDGMENTS}

This work was supported by the ANR CAPRICE 2011INTB 1001-01, the European C-MAC consortium, COST Action CM0904 "Intermetallic compounds as catalyst for steam reforming of methanol (IMC-SRM)," the CNRS (Project No. PICS-INCAS-05892), and the Brazilian research agency Conselho Nacional de Desenvolvimento Científico e tecnológico (CNPq) for financial support of this research. M.M. also acknowledges financial support from the "Région Lorraine" during his Ph.D. This work was granted access to the HPC resources of IDRIS under the allocation i2015096339.
[1] T. Tanabe, S. Kameoka, and A. P. Tsai, Appl. Catal., A 384, 241 (2010).

[2] M. Armbrüster et al., Nat Mater 11, 690 (2012).

[3] K. Urban and M. Feuerbacher, J. Non-Cryst. Solids 334-335, 143 (2004).

[4] J. Ledieu, É. Gaudry, and V. Fournée, Sci. Technol. Adv. Mater. 15, 034802 (2014).
[5] K. Kovnir et al., Sci. Technol. Adv. Mater. 8, 420 (2007).

[6] J. Ledieu, É. Gaudrey, L. N. Sekovic Loli, S. A. Villaseca, M.-C. de Weerd, M. Hahne, P. Gille, Y. Grin, J.-M. Dubois, and V. Fournée, Phys. Rev. Lett. 110, 076102 (2013).

[7] S. Song and E. R. Ryba, Philos. Mag. Lett. 65, 85 (1992).

[8] M. Armbrüster (private communication). 
[9] G. Trambly de Laissardière, D. Nguyen-Manh, and D. Mayou, Prog. Mater. Sci. 50, 679 (2005).

[10] A. Ormeci and Y. Grin, Isr. J. Chem. 51, 1349 (2011).

[11] A. G. C. Gwyer, Z. Anorg. Chem. 57, 113 (1908).

[12] A. J. Bradley and G. C. Seager, J. Inst. Metals 64, 81 (1939).

[13] U. Burkhardt, M. Ellner, Yu. Grin, and B. Baumgartner, Powder Diffr. 13, 159 (1998).

[14] K. W. Richter and D. T. Gutiérrez, Intermetallics 13, 848 (2005).

[15] S. Alarcón Villaseca, J. M. Dubois, and É. Gaudry, Philos. Mag. 91, 2894 (2011).

[16] T. Gödecke and M. Ellner, Z. Metallkd. 87, 854 (1996).

[17] A. J. Bradley and C. S. Cheng, Z. Kristallogr. 99, 480 (1938).

[18] F. Stein, C. He, and N. Dupin, Intermetallics 39, 58 (2013).

[19] A. Mayer, H. Salopaasi, K. Pussi, and R. Diehl, Comput. Phys. Commun. 183, 1443 (2012).

[20] A. Barbieri and M. A. Van Hove, http://www.icts.hkbu.edu.hk/ vanhove/

[21] J. Rundgren, Phys. Rev. B 68, 125405 (2003).

[22] J. B. Pendry, J. Phys. C: Solid State Phys. 13, 937 (1980).

[23] G. Kresse and J. Hafner, Phys. Rev. B 47, 558 (1993).

[24] G. Kresse and J. Hafner, Phys. Rev. B 49, 14251 (1994).

[25] G. Kresse and J. Furthmüller, J. Comput. Mater. Sci. 6, 15 (1996).

[26] G. Kresse and J. Furthmüller, Phys. Rev. B 54, 11169 (1996).

[27] P. E. Blochl, Phys. Rev. B 50, 17953 (1994).

[28] G. Kresse and D. Joubert, Phys. Rev. B 59, 1758 (1999).

[29] J. P. Perdew, K. Burke, and M. Ernzerhof, Phys. Rev. Lett. 77, 3865 (1996).

[30] J. P. Perdew, K. Burke, and M. Ernzerhof, Phys. Rev. Lett. 78, 1396 (1997).

[31] K. Momma and F. Izumi, J. Appl. Crystallogr. 44, 1272 (2011).

[32] M. Hagen and M. W. Finnis, Philos. Mag. A 77, 447 (1998).

[33] C. Colinet and J.-C. Tedenac, Intermetallics 18, 459 (2010).

[34] C. Colinet and J.-C. Tedenac, Comput. Mater. Sci. 85, 94 (2014).

[35] C. Colinet and J.-C. Tedenac, Intermetallics 17, 291 (2009).

[36] A. Togo, F. Oba, and I. Tanaka, Phys. Rev. B 78, 134106 (2008).

[37] R. Mittal, M. Zbiri, H. Schober, E. Marelli, S. J. Hibble, A. M. Chippindale, and S. L. Chaplot, Phys. Rev. B 83, 024301 (2011).

[38] N. Moll, A. Kley, E. Pehlke, and M. Scheffler, Phys. Rev. B 54, 8844 (1996).
[39] F. Bechstedt, Principles of Surface Physics (Springer, Berlin, 2003).

[40] W. G. Schmidt, Appl. Phys. A 75, 89 (2002).

[41] J. R. Kitchin, K. Reuter, and M. Scheffler, Phys. Rev. B 77, 075437 (2008).

[42] F. D. Boer et al., Cohesion in Metals (Elsevier, Amsterdam, 1988).

[43] M. Mihalkovič and M. Widom, Phys. Rev. B 75, 014207 (2007).

[44] M. Widom and J. A. Moriarty, Phys. Rev. B 58, 8967 (1998).

[45] G. Bester, B. Meyer, and M. Fähnle, Phy. Rev. B. 60, 14492 (1999).

[46] C. Kittel, Introduction to Solid State Physics (Wiley, New York, 1996).

[47] E. Belin-Ferré et al., J. Phys.: Condens. Matter 9, 9585 (1997).

[48] S. A. Villaseca et al., J. Phys. Chem. C. 115, 14922 (2011).

[49] M. Mihalkovič, H. Elhor, and J. B. Suck, Phys. Rev. B 63, 214301 (2001).

[50] G. Trambly de Laissardière, D. N. Manh, L. Magaud, J. P. Julien, F. Cyrot-Lackmann, and D. Mayou, Phys. Rev. B 52, 7920 (1995).

[51] M. Oku, T. Shishido, H. Matsuta, and K. Wagatsuma, J. Electron Spectrosc. Relat. Phenom. 153, 75 (2006).

[52] K. G. Nath, Y. Haruyama, and T. Kinoshita, Phys. Rev. B 64, 245417 (2001).

[53] F. U. Hillebrecht, J. C. Fuggle, P. A. Bennett, Z. Zolnierek, and Ch. Freiburg, Phys. Rev. B 27, 2179 (1983).

[54] J. Tersoff and D. R. Hamann, Phys. Rev. Lett. 50, 1998 (1983).

[55] J. Tersoff and D. R. Hamann, Phys. Rev. B 31, 805 (1985).

[56] M. Krajčí and J. Hafner, Phys. Rev. B 80, 214419 (2009).

[57] M. Gatti, Ab initio Calculations of Many-Body Effects in Electronic Spectra (École Polytechnique, Palaiseau, 2007)

[58] J. Grin, U. Burkhardt, M. Ellner, and K. Peters, J. Alloys Compd. 206, 243 (1994).

[59] Complex Metallic Alloys: Fundamentals and Applications, edited by J.-M. Dubois and E. Belin-Ferré (Wiley-VCH, Weinheim, 2011).

[60] H. Shin et al., Phys. Rev. B 84, 085411 (2011).

[61] V. Fournée, É Gaudry, M.-C. de Weerd, R. D. Diehl, and J. Ledieu, Symposium KK - Complex Metallic Alloys, MRS Online Proceedings Library (Cambridge University Press, Cambridge, UK, 2012), Vol. 1517. 